\title{
Development of a New Class of Low Cost, High Frequency Link Direct DC to AC Converters for Solid Oxide Fuel Cells (SOFC)
}

\author{
By \\ Drs. Prasad Enjeti \& J.W. Howze \\ Power Electronics \& Fuel Cell Power Conditioning Laboratory \\ Department of Electrical Engineering \\ Texas A\&M University \\ College Station, TX - 77845 \\ Tel: 979-845-7466 \\ Email: enjeti@ee.tamu.edu \\ Submitted to: \\ U.S. Department of Energy \\ Solid State Energy Conversion Alliance (SECA) Core Technology Program \\ Proposal for: Solicitation Number: DE-PS26-02NT40854-4.2
}

Date:

December 2003

“This report was prepared as an account of work sponsored by an agency of the United States Government. Neither the United States Government nor any agency thereof, nor any of their employees, makes any warranty, express or implied, or assumes any legal liability or responsibility for the accuracy, completeness, or usefulness of any information, apparatus, product, or process disclosed, or represents that its use would not infringe privately owned rights. Reference herein to any specific commercial product, process, or service by trade name, trademark, manufacturer, or otherwise does not necessarily constitute or imply its endorsement, recommendation, or favoring 
by the United States Government or any agency thereof. The views and opinions of authors expressed herein do not necessarily state or reflect those of the United States Government or any agency thereof.” 


\title{
Development of a New Class of Low Cost, High Frequency Link Direct DC to AC Converters for Solid Oxide Fuel Cells (SOFC)
}

\author{
Dr. Prasad Enjeti \\ Power Electronics \& Fuel Cell Power Conditioning Laboratory \\ Department of Electrical Engineering \\ Texas A\&M University \\ College Station, TX - 77845 \\ Tel: $979-845-7466$ \\ Email: enjeti@ee.tamu.edu
}

\section{PROJECT DESCRIPTION}

This project proposes to design and develop a new class of power converters (direct DC to $\mathrm{AC}$ ) to drastically improve performance and optimize the cost, size, weight and volume of the DC to AC converter in SOFC systems. The proposed topologies employ a high frequency link; direct $\mathrm{DC}$ to $\mathrm{AC}$ conversion approach. The direct $\mathrm{DC}$ to $\mathrm{AC}$ conversion approach is more efficient and operates without an intermediate dc-link stage. The absence of the dc-link, results in the elimination of bulky, aluminum electrolytic capacitors, which in turn leads to a reduction in the cost, volume, size and weight of the power electronic converter.

The feasibility of two direct DC to AC converter topologies and their suitability to meet SECA objectives will be investigated. Laboratory proto-type converters (3-5kW) will be designed and tested in Phase-1. A detailed design trade-off study along with the test results will be available in the form of a report for the evaluation of SECA Industrial partners. 
Period of Performance: $10 / 01 / 2002$ to 09/30/2003

Project Participants: Industrial partner Delphi-Auto

Project Costs:
A. DOE Costs : $\$ 150,000$
B. Prime Cost Sharing : $\$ 37,500$
C. Partner Cost Sharing, If Applicable : None (in kind)

\section{Il. Objectives:}

This project proposes to develop a new and innovative power converter technology suitable for Solid Oxide Fuel Cell (SOFC) power systems in accordance with SECA objectives. The proposed fuel cell inverter $(\mathrm{FCl})$ employs state of the art power electronic devices configured in two unique topologies to achieve direct conversion of DC power (24-48V) available from a SOFC to AC power $(120 / 240 \mathrm{~V}, 60 \mathrm{~Hz})$ suitable for utility interface and powering stand alone loads. The primary objective is to realize cost effective fuel cell converter, which operates under a wide input voltage range, and output load swings with high efficiency and improved reliability.

\section{Results and Discussion: (June, 2003)}

As detailed in Phase-1 statement of project objectives (SOPO) scope of work section, three direct DC to AC conversion approaches (Fig. 3a, Fig. 3b and Fig. 3bb) were listed to be evaluated during the course of the project. The next few sections describe this work in more detail. 


\section{III.1 Evaluation of Direct DC to AC Single phase AC Output Converter (Fig. 3a in}

\section{Phase-1 SOPO):}

Fig. 1 shows the complete topology (of Fig. 3a Phase-1 SOPO) of the proposed currentfed HF link DC/AC converter with an active harmonic filter for fuel cell applications. This consists of the full-bridge current-fed HF link DC/AC converter and active harmonic filter. The converter generates split phase AC outputs from a fuel cell powered DC source. The function of the active harmonic filter is to compensate for low frequency 120 $\mathrm{Hz}$ current from the fuel cell.

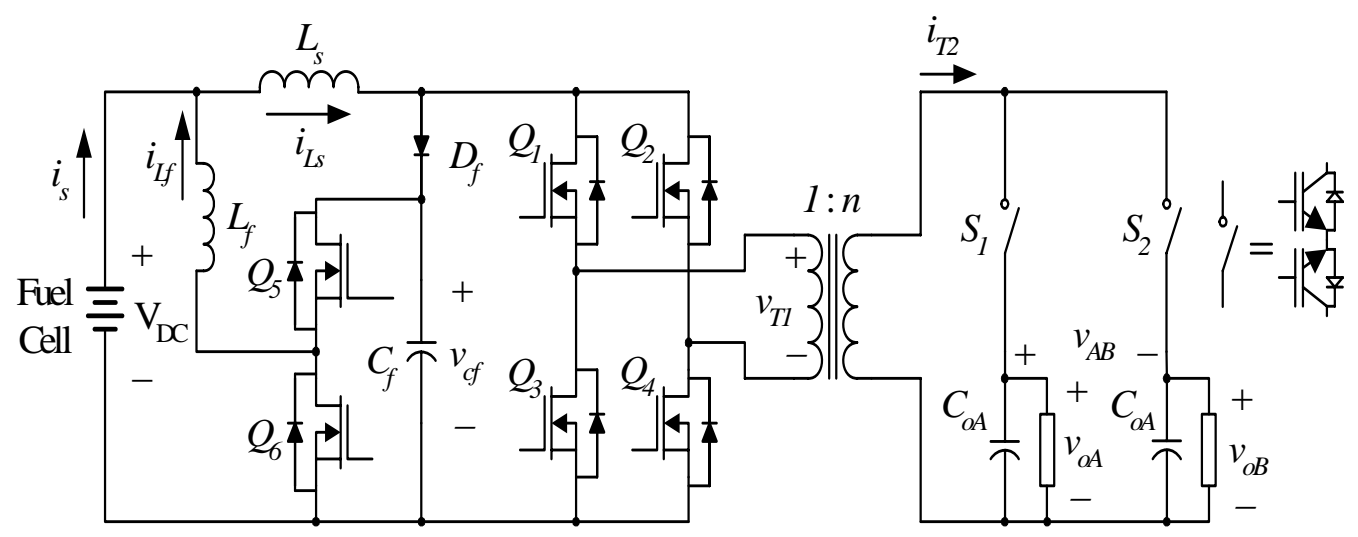

Fig.1 Proposed current-fed HF link DC/AC converter (The above converter concept is discussed in Fig. 3a of Phase-1 SOPO)

The proposed current-fed HF link DC/AC converter has a single stage without the buck regulation stage, which consists of the primary inductor $\left(L_{s}\right)$, full-bridge inverter $\left(Q_{1}-Q_{4}\right)$, HF transformer, two bi-directional switches $\left(S_{1}\right.$ and $\left.S_{2}\right)$, and output capacitors $\left(C_{O A}\right.$ and $C_{O B}$ ). The diode $D_{f}$ and capacitor $C_{f}$ in the active filter are used for the voltage clamping in the main HF link inverter operation without the additional claming circuits. The fullbridge configuration offers the low switch stress, simple voltage clamping, and simple structure and easy balancing of the HF transformer as compared with the push-pull configuration. Moreover, the secondary side has the simplest structure with only two bidirectional switches and capacitors. 


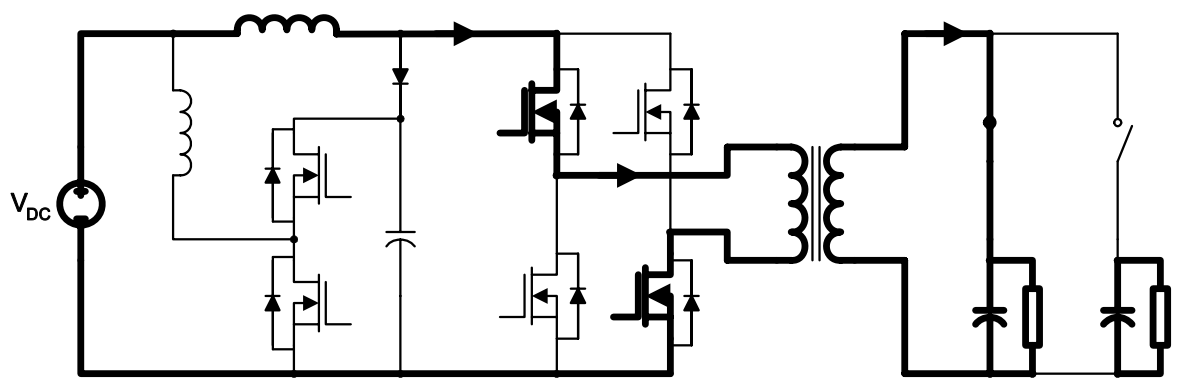

(a)

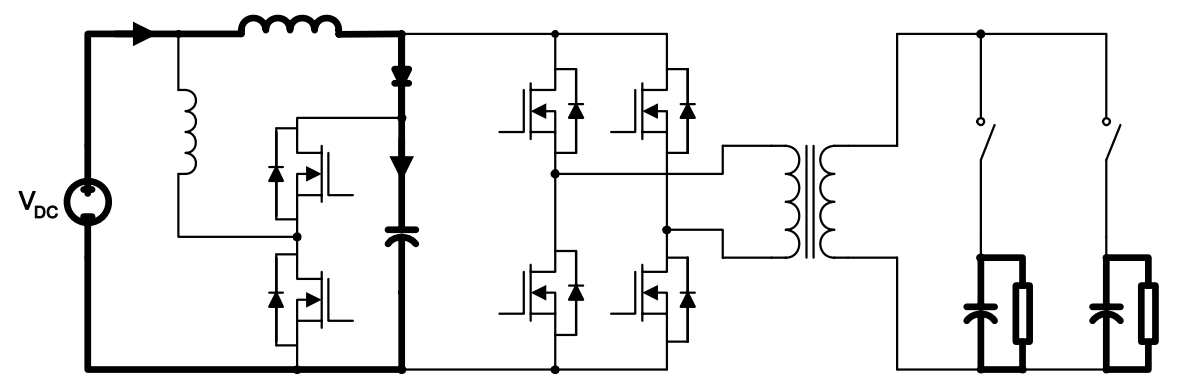

(b)

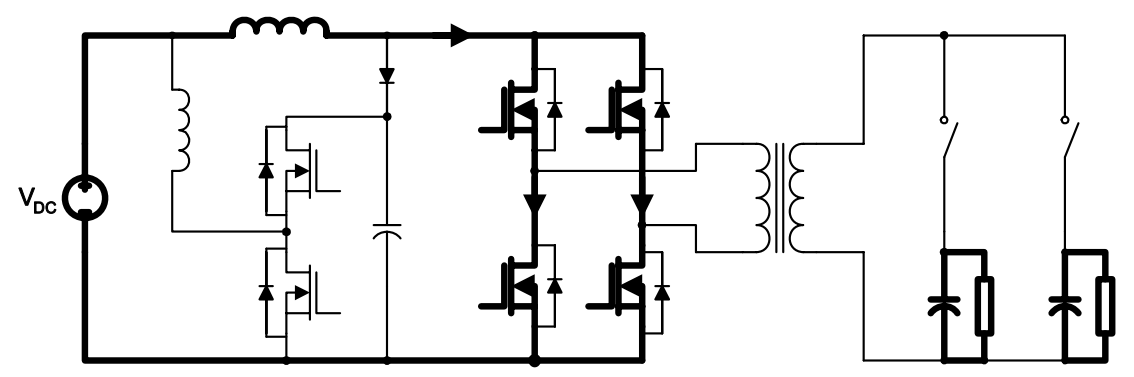

(c)

Fig. 2 Operating modes of current-fed HF link DC/AC converter. (a) Powering mode (b) Reset mode (c) Restoring mode

There are three operating modes in the proposed DC/AC converter; the powering, reset, and restoring modes.

Powering mode: Two diagonal switches $\left(Q_{1}\right.$ and $Q_{4}$, or $Q_{2}$ and $\left.Q_{3}\right)$ are closed in the powering mode as shown in Fig. 2(a). The current $i_{L s}$ of the primary inductor is sinusoidally modulated by the full-bridge inverter and transferred to the output through the HF transformer and bi-directional switch. One of two bi-directional switches is closed according to the polarities of the link current and desired output voltage. To minimize the switching losses, the bi-directional switches are turned on/off at the zero link current. 
Reset mode: Two upper or lower switches $\left(Q_{1}\right.$ and $Q_{2}$, or $Q_{3}$ and $\left.Q_{4}\right)$, or all four switches are opened in the reset mode as shown in Fig. 2(b). The inductor current $i_{L S}$ flows through the diode $D_{f}$ and charges the capacitor $C_{f}$. The primary inductor is generally reset through a flyback winding in the conventional current-fed approaches [9], [10], which has the complexity of the inductor and produces a high impact current. These disadvantages are easily overcome in the proposed scheme. The capacitor voltage $v_{C f}$ can be controlled by the switches $Q_{5}$ and $Q_{6}$ during the active filter operation and is maintained to be higher than the input voltage $V_{d c}$ and the transformer primary voltage $v_{T 1}$.

Restoring mode: Both switches of one inverter leg $\left(Q_{1}\right.$ and $Q_{3}$, or $Q_{2}$ and $\left.Q_{4}\right)$, or all four switches are closed as shown in Fig. 2(c). Thus, the inductor current increases with a rate of $V_{d d} / L_{s}$ in the restoring mode while decreases with a rate of $\left(V_{d c}-V_{C f}\right) / L_{s}$ in the reset mode. Therefore, the primary inductor current can be controlled by the appropriate selection of the reset and restoring mode during the interval that the primary current is not transferred to the secondary side.

\section{Active Cancellation of $120 \mathrm{~Hz}$ Input Harmonic Current:}

The input and output powers of the inverter should be balanced in both average and instantaneous senses. The output voltage and current of the DC/AC converter with a sinusoidal output can be expressed as

$$
\begin{aligned}
& v_{o}(t)=\sqrt{2} V_{\text {rms }} \sin \omega t \\
& i_{o}(t)=\sqrt{2} I_{\text {rms }} \sin (\omega t-\phi)
\end{aligned}
$$

where $\phi$ denotes a power factor angle. The instantaneous power is derived from (1) and (2) as

$$
\begin{aligned}
p_{o}(t) & =v_{o}(t) i_{o}(t) \\
& =V_{r m s} I_{r m s} \cos \phi-V_{r m s} I_{r m s} \cos (2 \omega t-\phi)
\end{aligned} .
$$

The average power is defined as

$$
P_{a v}=V_{\text {rms }} I_{r m s} \cos \phi .
$$

The input current for a constant input voltage of $V_{d c}$ can be represented as 
$i_{s}(t)=\frac{V_{r m s} I_{r m s}}{V_{d c}} \cos \phi-\frac{V_{r m s} I_{r m s}}{V_{d c}} \cos (2 \omega t-\phi)$.

The second term of the right hand side in (2) is the second order ripple current defined as

$$
i_{r}(t)=-\frac{V_{r m s} I_{r m s}}{V_{d c}} \cos (2 \omega t-\phi) .
$$
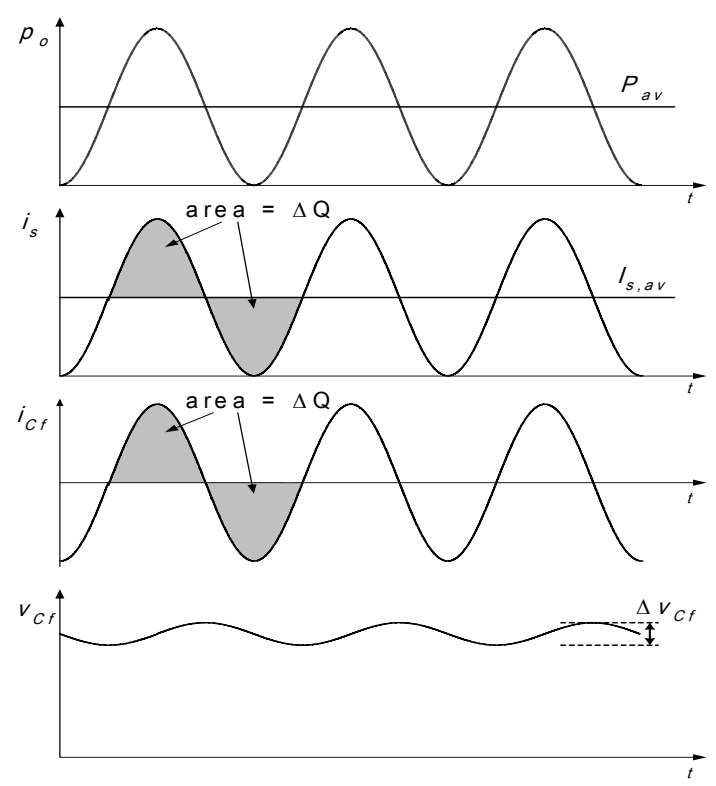

Fig. 3 Output power, input current, capacitor current and voltage waveforms

The basic concept of the proposed technique is that the capacitor $C_{f}$ stores the charge $\Delta Q$ from the DC source during the negative half cycle of the ripple current and then supplies the stored charge to the output during the positive half. Fig. 3 shows the output power, input current, net capacitor current, and capacitor voltage. The charge $\Delta Q$ is equal to the area of the half cycle and can be represented as

$$
\Delta Q=\sqrt{2} I_{r m s} / 60 \pi .
$$

The voltage ripple of the filter capacitor $C_{f}$ can be calculated from (7) as

$$
\Delta v_{C f}=\Delta Q / C_{f} .
$$

Fig. 4 shows the operation of the active harmonic filter, where it is assumed that the filter capacitor voltage $v_{c f}$ is controlled to be higher than $V_{d c}$ and $v_{T 1}$. Two operating modes can be considered for the active filter operation. One is the buck mode as shown 
in Fig. 4(a). The switch $Q_{5}$ and diode $D_{6}$ operates in this mode and the stored charge supplies to the output through the filter inductor $L_{f}$. The other is the boost mode as shown in Fig. 4(a). The current of the filter inductor flows from the source to the filter capacitor and the filter capacitor is charged by the boosting action of the switch $Q_{6}$ and diode $D_{5}$
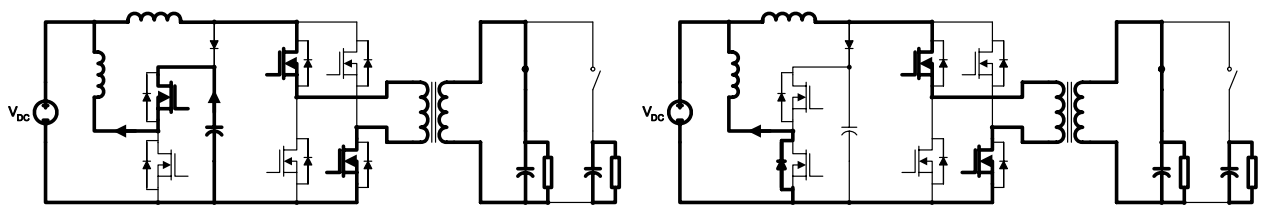

(a)

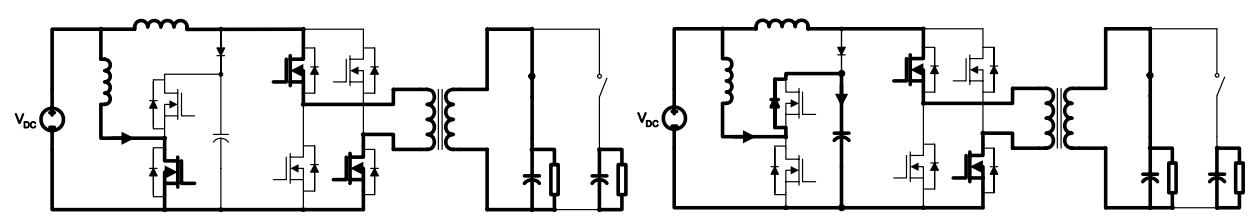

(b)

Fig. 4 Operating modes of active harmonic filter. (a) Buck mode (b) Boost mode

\section{Control of Output Voltage}

Fig. 5(a) shows the voltage control scheme for the main DC/AC converter. The output voltage is controlled by the PWM of the full-bridge inverter, where $G_{v}(s)$ is the gain of the voltage control loop. A simple proportional $(P)$ control is used for $G_{v}(\mathrm{~s})$. The bi-directional switches $S_{1}$ ans $S_{2}$ in the secondary side are selected according to the polarities of the control input and link current as shown in Fig. 5(b). Fig. 6 shows the current control scheme for the primary inductor. The inductor current is controlled by choosing the reset or restoring mode. The current reference can be calculated from the average output power. An integrator with a reset is used as a controller. The reset mode is selected $x_{k}>0$ and the restoring mode is selected when $x_{k}<0$, where $x_{k}=Z_{k=>I}\left[i_{L s}^{*}(t)-i_{L S}(t)\right] d t$ and $T$ is the switching period. 


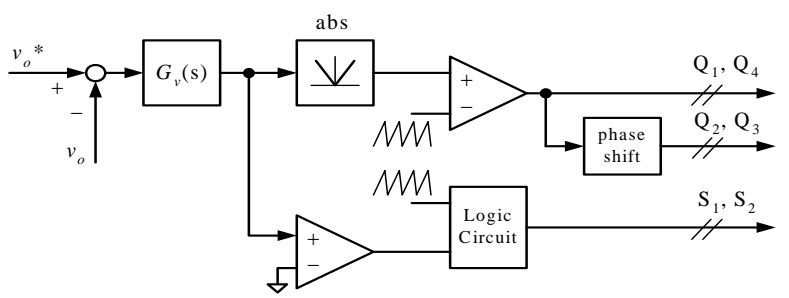

(a)

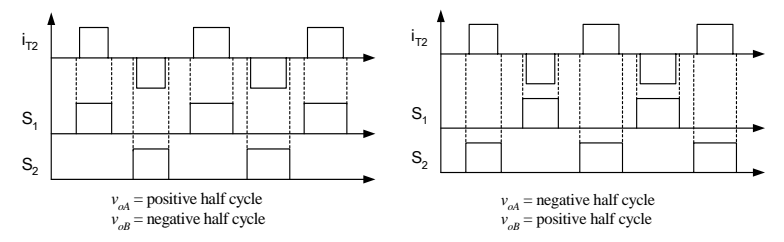

(b)

Fig. 5 Voltage control for current-fed HF link DC/AC converter. (a) Voltage control scheme (b) Switching method of bi-directional switches

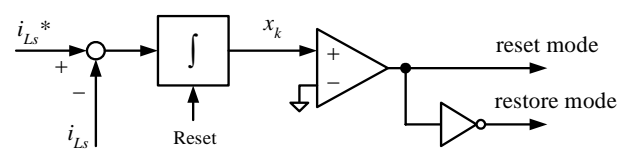

Fig. 6 Current control scheme for the primary inductor

\section{Design Example and Performance Waveforms:}

The proposed converter (Fig. 1) was fully analyzed and simulated. The simulation was done with the following design values: $V_{d c}=48 \mathrm{~V}, f_{s}=20 \mathrm{kHz}, L_{s}=500 \mathrm{uH}, L_{f}=500 \mathrm{uH}$, $C_{O A}=C_{O B}=50 \mathrm{uF}, C_{f}=5600 \mathrm{uF}, n=4$, where $f_{s}$ and $n$ denote the switching frequency and transformer turn ratio, respectively. The gains of the voltage controller was set at $G_{s}(s)=K_{s}=10$. The PI control is used as for $G_{f}(s)$ and the gains are given as $K_{p}=100$ and $K_{i}=5000$ respectively. Fig. 8 shows the simulation results of the proposed DC/AC converter for the output load of $1.5 \mathrm{~kW}$ in each phase. Figs. 8 (a) shows the $120 / 240 \mathrm{~V} 1-$ phase output voltages Figs. 8 (b), (c), (d), and (e) represents the operation of the active harmonic filter, and shows the primary inductor current, filter inductor current, input current, and filter capacitor voltage, respectively. It is noted that the fuel cell input 
current is nearly DC and the $120 \mathrm{~Hz}$ current has been considerably reduced due to the active filter operation.

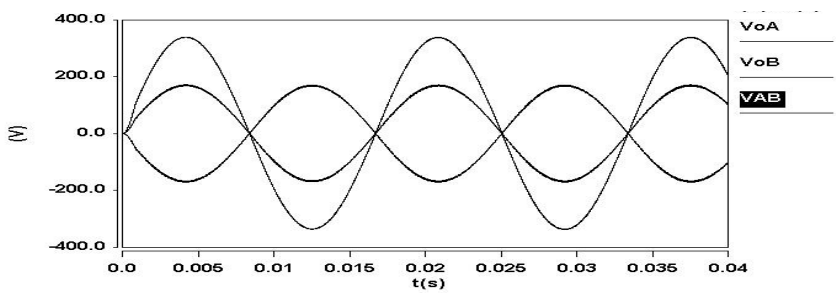

(a)

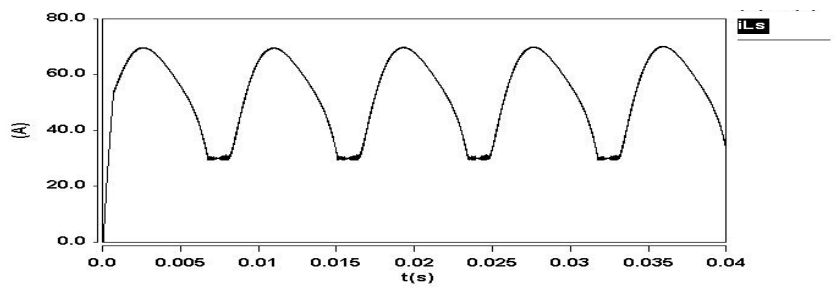

(b)

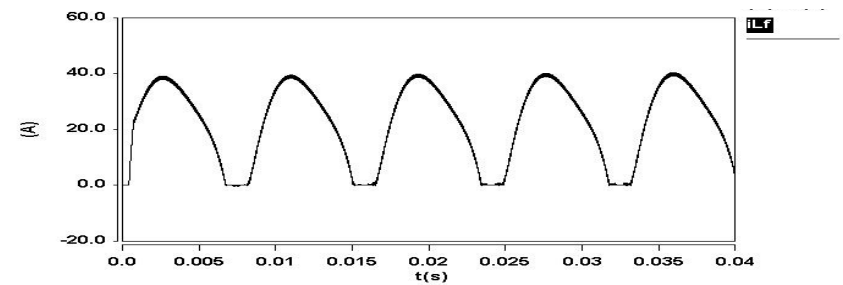

(c)

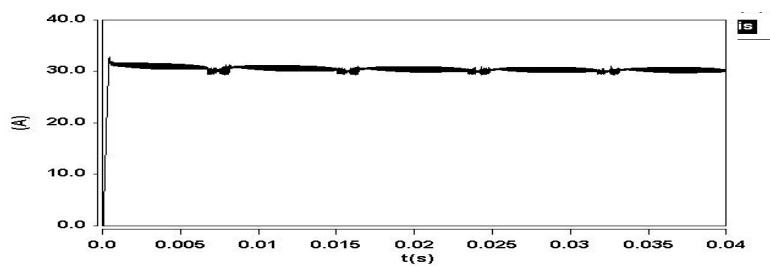

(d)

Fig. 7 Simulation results of the converter shown in Fig. 1. (a) output ac voltage, (b) input dc current, (c) active filter current, (d) fuel cell input current

\section{Conclusions:}

In Fig. 1 a new current-fed HF link DC/AC converter with the capability of producing $120 \mathrm{~V} / 240 \mathrm{~V}$ ac output voltage has been discussed. The proposed converter is a single stage approach and has a simple transformer structure. The active harmonic filter consists of the two switches and one electrolytic capacitor, and effectively eliminates the input harmonic current. The operation of the DC/AC converter and harmonic filter has been fully investigated. Extensive computer simulations have been carried out under various loading conditions. The following are the broad conclusions:

- Although the converter performance is within the specifications, the output voltage is susceptible to load changes, difficult to control.

- Incorporating a battery in this design is difficult. Furthermore the transformer rating is higher compared to other schemes This does not meet the DELPHI PCU specifications 
- Further work on this converter is suspended.

\section{III.2 Evaluation of Direct DC to AC Single phase AC Output Converter (Fig. 3b in}

\section{Phase-1 SOPO):}

Fig. 8 shows the complete topology of another direct DC to AC converter discussed in Phase-1 (see Fig. 3b in Phase-1, SOPO). In this approach the fuel cell DC input voltage

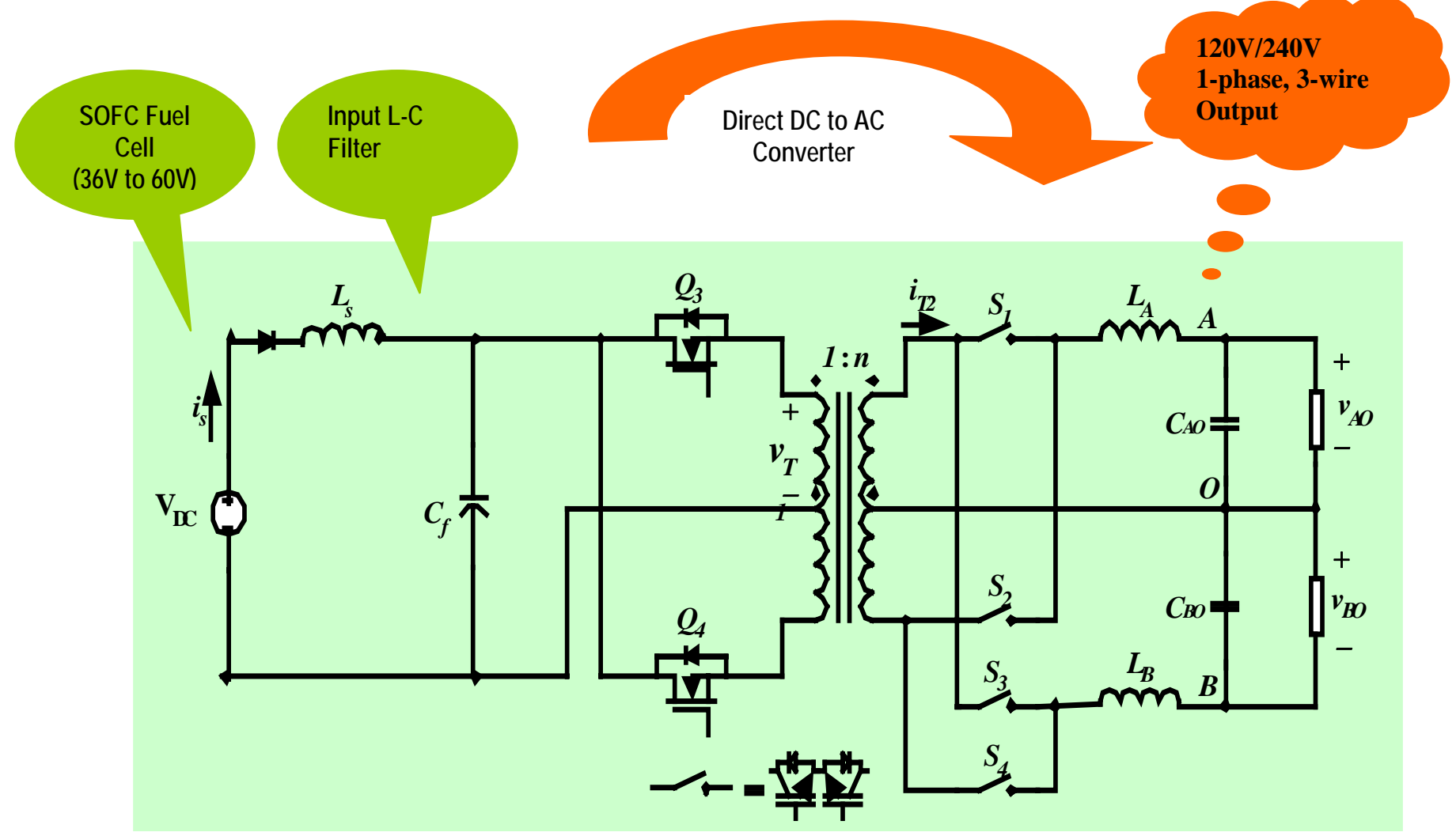

Fig. 8 Proposed voltage source type direct DC to AC converter for SOFC without a Battery (The above converter concept is discussed in Fig. 3b of Phase-1 SOPO)

is processed via a high frequency link MOSFET converter via a transformer isolation. The high frequency transformer provides isolation as well as facilitates the step-up in voltage. The secondary side converter is composed of bi-directional switches which directly converts to low frequency ac output. A two MOSFET switches (Q3 and Q4) are connected in push-pull fashion for converting the SOFC voltage (36V) to high frequency 
and the secondary of the transformer is interfaced with switches S1 to S4 to perform direct DC to 1-phase 120V/240V, 60Hz, 3-wire AC output.

\section{III.2.1 Design Example and Performance Results:}

Appendix-1 of this document consists of SOFC power conditioning unit (PCU) technical specifications supplied by DELPHI. TAMU design for the proposed converter has centered around these specifications. Table-1 and Table-2 shows the converter component ratings to meet the specifications. Fig. 9 to Fig. 11 shows the waveforms obtained from simulations.

Output power: $\quad 5 \mathrm{~kW}$ (resistive)

Output voltage: $\quad 120 \mathrm{~V} / 240 \mathrm{~V}, 1$-phase, $60 \mathrm{~Hz}, 3$-wire output

Output current: $\quad 20.7$ A (rms.), 29.3 A (peak)

Switching frequency: $\quad 20 \mathrm{kHz}$

Table 1

\begin{tabular}{|c|c|c|c|c|c|c|c|}
\hline $\begin{array}{c}\text { Input } \\
\text { voltage } \\
\text { Vdc[V] }\end{array}$ & $\begin{array}{c}\text { Turn } \\
\text { ratio } \\
\mathrm{N} 2 / \mathrm{N} 1\end{array}$ & $\begin{array}{c}\mathrm{L}_{1} \\
{[\mathrm{uH}]}\end{array}$ & $\begin{array}{c}\mathrm{L}_{2} \\
{[\mathrm{nH}]}\end{array}$ & $\begin{array}{c}\mathrm{C}_{1} \\
{[\mathrm{~F}]}\end{array}$ & $\begin{array}{c}\mathrm{C}_{2} \\
{[\mathrm{~F}]}\end{array}$ & $\begin{array}{c}\mathrm{L}_{\mathrm{A}} \\
{[\mathrm{mH}]}\end{array}$ & $\begin{array}{c}\mathrm{C}_{\mathrm{AO}} \\
{[\mathrm{uF}]}\end{array}$ \\
\hline 36 & $16 / 3$ & 1 & 5 & 30 & 0.5 & 1 & 50 \\
\hline
\end{tabular}

Table 2

\begin{tabular}{|c|c|c|c|c|c|c|c|c|}
\hline $\begin{array}{c}\mathrm{Vi} \\
{[\mathrm{V}]}\end{array}$ & $\begin{array}{c}\mathrm{V}_{\mathrm{Q} 3 . \mathrm{rms}} \\
{\left[\mathrm{V}_{\text {rms }}\right.}\end{array}$ & $\begin{array}{c}\mathrm{I}_{\mathrm{Q} . \mathrm{pk}} \\
{[\mathrm{A}]}\end{array}$ & $\begin{array}{c}\mathrm{V}_{\mathrm{S1} 1 \mathrm{rms}} \\
{\left[\mathrm{V}_{\mathrm{rms}}\right]}\end{array}$ & $\begin{array}{c}\mathrm{I}_{\mathrm{S} 1 . \mathrm{pk}} \\
{[\mathrm{A}]}\end{array}$ & $\begin{array}{c}\mathrm{I}_{\mathrm{A}, \mathrm{rms}} \\
{\left[\mathrm{A}_{\mathrm{rms}}\right]}\end{array}$ & $\begin{array}{c}\mathrm{I}_{\mathrm{A}, \mathrm{pk}} \\
{[\mathrm{A}]}\end{array}$ & $\begin{array}{c}\mathrm{I}_{\mathrm{T} 2, \mathrm{rms}} \\
{\left[\mathrm{A}_{\mathrm{rms}}\right]}\end{array}$ & $\begin{array}{c}\mathrm{I}_{\mathrm{T} 2, \mathrm{pk}} \\
{[\mathrm{A}]}\end{array}$ \\
\hline 36 & 50.7 & 365.5 & 270.8 & 32.1 & 21.1 & 32.4 & 19.7 & 33.6 \\
& $0.42 \mathrm{p} . \mathrm{u}$ & $12.5 \mathrm{p} . \mathrm{u}$ & $2.3 \mathrm{p} . \mathrm{u}$ & $1.1 \mathrm{p} . \mathrm{u}$ & $1 \mathrm{p} . \mathrm{u}$ & $1.1 \mathrm{p} . \mathrm{u}$ & $0.95 \mathrm{p} . \mathrm{u}$ & $1.1 \mathrm{p} . \mathrm{u}$ \\
\hline
\end{tabular}




\section{Waveforms}

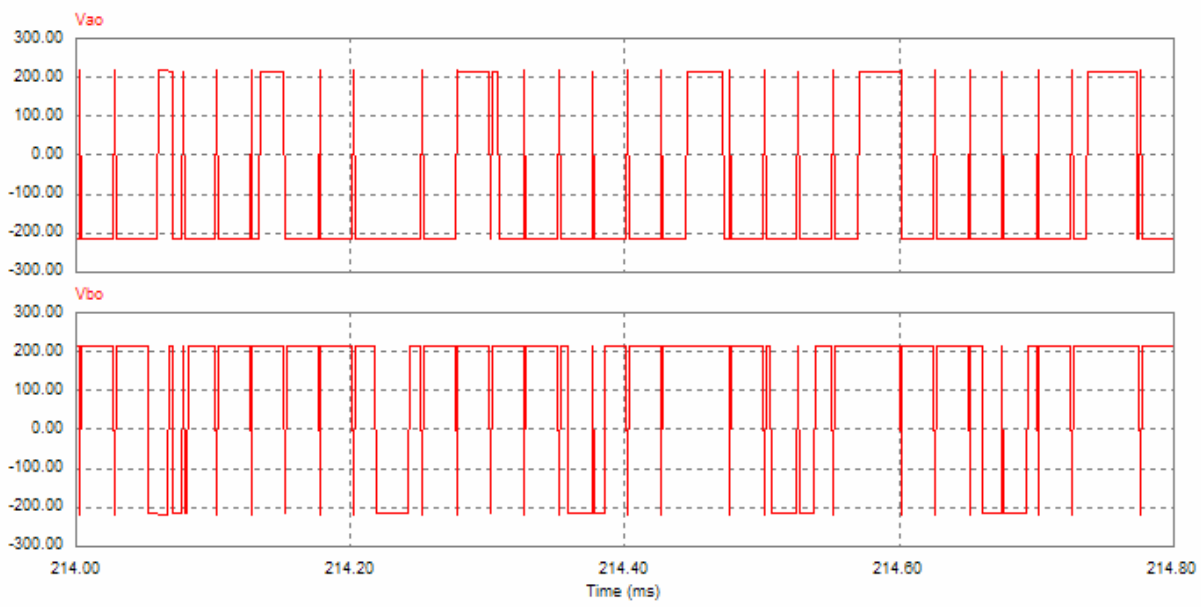

Fig. 9 Unfiltered output voltage of the direct DC to AC converter shown in Fig. 8
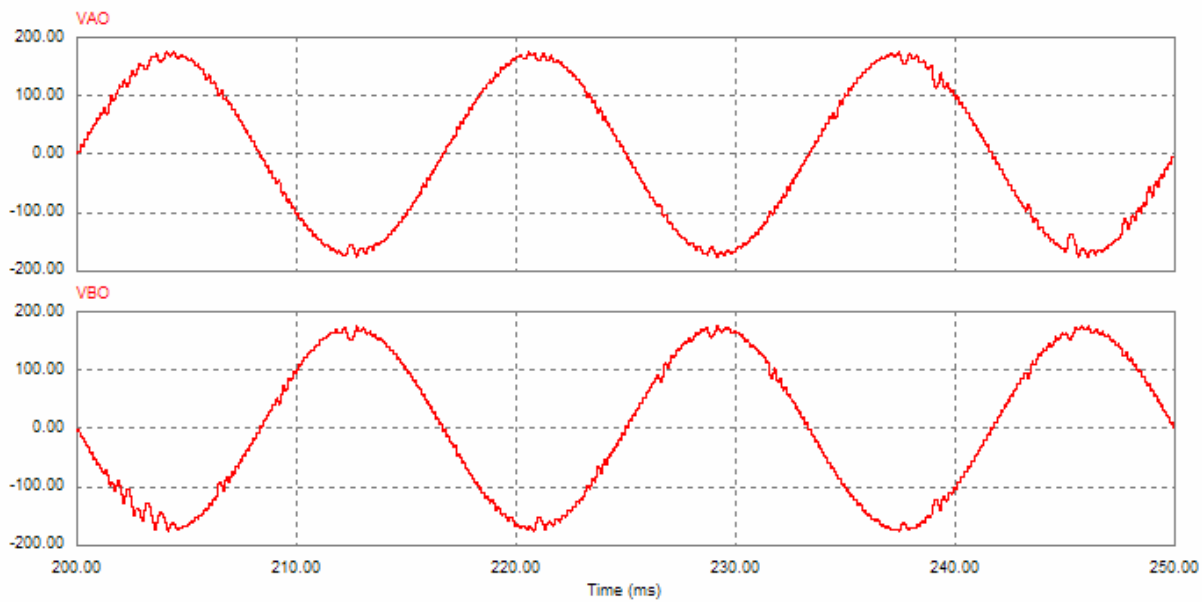

Fig. 10a Single phase 120V/240V, 60Hz, 3-wire output voltage of the direct DC to AC converter of Fig. 8

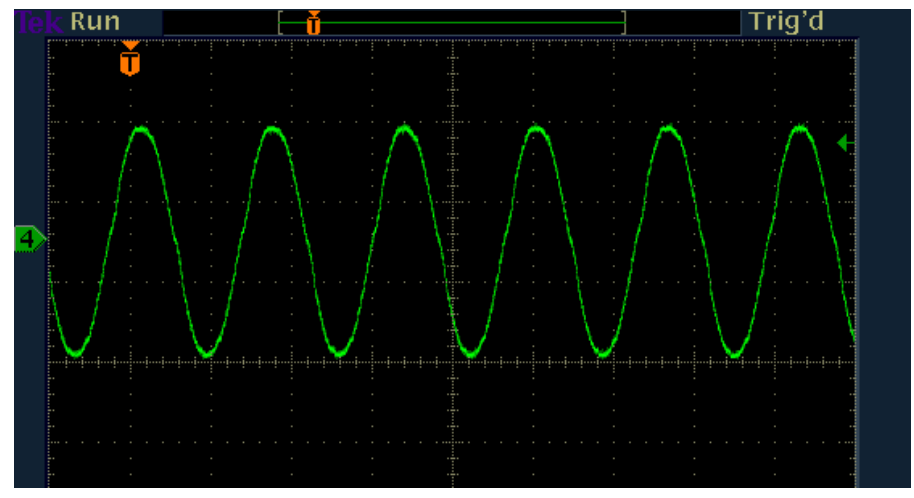

Fig. 10b Experimental results (output ac voltage for phase A) 


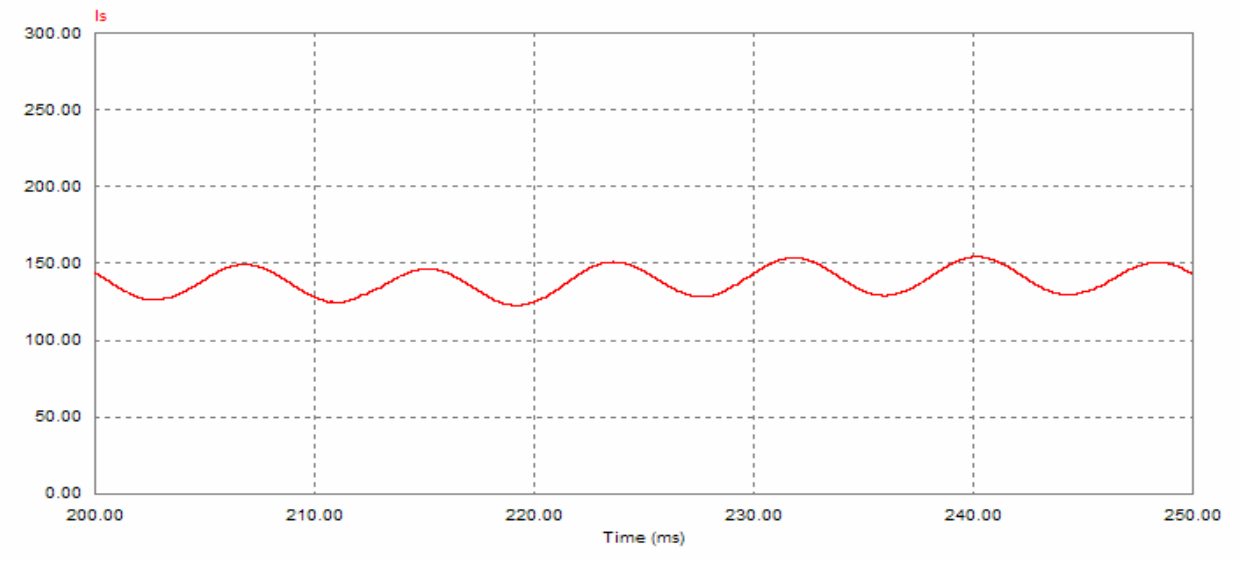

Fig. 11 Fuel cell input current waveform

\section{III.2.2 Conclusions:}

From the results obtained in Phase-1 it can be concluded that the topology shown in Fig. 8 has several advantages compared to the prior art:

- A 3kW converter shown has been successfully constructed and tested. An overall efficiency of $90 \%$ was measured. There is still room for improvement by reducing the transformer leakage and by improving the four-step switching strategy of the bidirectional switches. These will be pursued in Phase 2 of the project.

- Due to absence of dc-link capacitors, a low profile converter construction can be adopted resulting in a higher density package.

- Higher reliability because the control of the primary side push-pull converter is simple and operates at $50 \%$ fixed duty cycle.

- Zero voltage switching of the switching converter on primary side uses magnetizing current inherent in the HF transformer and can be achieved. This aspect is under further investigation. 
- An optimized $2^{\text {nd }}$ order input filter at the input terminals guarantees the fuel cell input current to contain minimum input current ripple (see Fig. 8 and Fig. 11).

- The output of the converter can be altered from 1-phase to 3-phase by a simple change in software. 


\section{III.3 Evaluation of Direct DC to AC Single phase AC Output Converter (Fig. 3b in}

\section{Phase-1 SOPO) With Battery Backup Option:}

From the technical specifications obtained from DELPHI for the SOFC power conditioning unit (PCU) (see Appendix-1) it is clear that a battery back up option need to be explored for the PCU to satisfy stand-alone and UPS modes of operation. In order to comply to these specifications, the converter topology shown in Fig. 8 has been modified as shown in Fig. 12.

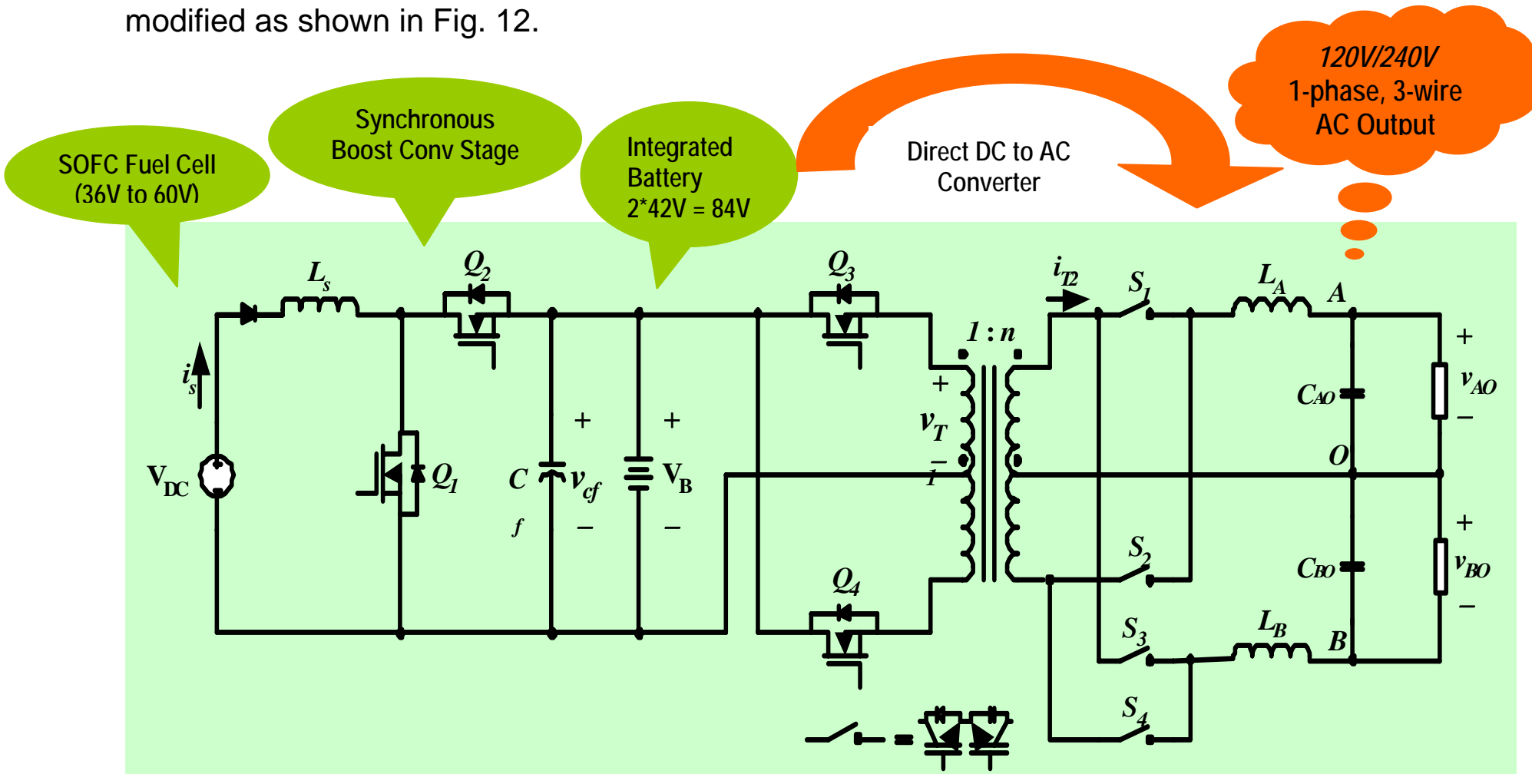

Fig. 12 Proposed voltage source type direct DC to AC converter for SOFC Power Conditioning Unit (PCU) with an Integrated Battery

Fig. 12 shows the direct DC to AC converter topology with integrated battery backup concept suitable for operating modes Mode 1 and Mode 4. In this approach the SOFC output ( $36 \mathrm{~V}$ to $60 \mathrm{~V}$ ) is first processed via a synchronous boost converter and is converted to $84 \mathrm{~V}$. Two $42 \mathrm{~V}$ batteries (connected in series to obtain $84 \mathrm{~V}$ ) are connected 
at the output of the boost stage. The direct DC to AC converter stage then converts the $84 \mathrm{~V}$ DC to $120 \mathrm{~V} / 240 \mathrm{~V}$ 1-phase 3-wire output. The push-pull stage of the direct DC to AC converter in this design (Fig. 12) sees a fixed 84V DC at its input and its design is optimized for full load operation of 5kW. Comparing Fig. 8 and Fig. 12 one notes that the direct $\mathrm{DC}$ to $\mathrm{AC}$ converter along with the high-frequency transformer in Fig. 12 will be smaller in size and more efficient than Fig. 8 design. This increase in conversion efficiency is expected to be compensated by the addition of the synchronous boost stage in Fig. 12. Therefore the overall efficiency of Fig. 8 and Fig. 12 designs should be comparable. Integrating the battery within the power conversion stage has many advantages and can meet the DELPHI described PCU operating modes 1 and 4 .

\section{III.3.1 Design Example and Performance Results:}

Appendix-1 of this document consists of SOFC power conditioning unit (PCU) technical specifications supplied by DELPHI. TAMU design for the proposed converter has centered around these specifications. Table- 3 to Table 5 show the converter component ratings to meet the specifications. Fig. 13 to Fig. 15 shows the waveforms obtained from simulations.

Output power:

Output voltage:

Output current:

Switching frequency:
$5 \mathrm{~kW}$ (resistive)

120V/240V, 1-phase, $60 \mathrm{~Hz}$, 3-wire output

20.7 A (rms.), 29.3 A (peak)

$20 \mathrm{kHz}$

Table 3

\begin{tabular}{|c|c|c|c|c|c|}
\hline $\begin{array}{c}\text { Input } \\
\text { voltage } \\
\text { Vdc[V] }\end{array}$ & $\begin{array}{c}\text { Turn } \\
\text { ratio } \\
\mathrm{N} 2 / \mathrm{N} 1\end{array}$ & $\begin{array}{c}\mathrm{L}_{\mathrm{s}} \\
{[\mathrm{uH}]}\end{array}$ & $\begin{array}{c}\mathrm{C}_{\mathrm{f}} \\
{[\mathrm{uF}]}\end{array}$ & $\begin{array}{c}\mathrm{L}_{\mathrm{A}} \\
{[\mathrm{mH}]}\end{array}$ & $\begin{array}{c}\mathrm{C}_{\mathrm{AO}} \\
{[\mathrm{uF}]}\end{array}$ \\
\hline 36 & $5 / 2$ & 10 & 2500 & 1 & 50 \\
\hline
\end{tabular}

Table 4

\begin{tabular}{|c|c|c|c|c|c|c|}
\hline $\mathrm{Vi}$ & $\mathrm{V}_{\text {Q1.rms }}$ & $\mathrm{I}_{\mathrm{Q} 1 . p k}$ & $\mathrm{~V}_{\mathrm{Q} 2 . \mathrm{rms}}$ & $\mathrm{I}_{\text {Q2.pk }}$ & $\mathrm{V}_{\mathrm{Q} 3 . r m s}$ & $\mathrm{I}_{\text {Q3.pk }}$ \\
\hline
\end{tabular}




\begin{tabular}{|c|c|c|c|c|c|c|}
\hline$[\mathrm{V}]$ & {$\left[\mathrm{V}_{\text {rms }}\right]$} & {$[\mathrm{A}]$} & {$\left[\mathrm{V}_{\text {rms }}\right]$} & {$[\mathrm{A}]$} & {$\left[\mathrm{V}_{\text {rms }}\right]$} & {$[\mathrm{A}]$} \\
\hline 36 & 50.8 & 145.7 & 67 & 143.5 & 118.7 & 182.2 \\
& $0.42 \mathrm{p} . \mathrm{u}$ & $5 \mathrm{p} . \mathrm{u}$ & $0.56 \mathrm{p} . \mathrm{u}$ & $4.9 \mathrm{p} . \mathrm{u}$ & $0.99 \mathrm{p} . \mathrm{u}$ & $6.2 \mathrm{p} . \mathrm{u}$ \\
\hline
\end{tabular}

Table 5

\begin{tabular}{|c|c|c|c|c|c|}
\hline $\begin{array}{c}\mathrm{V}_{\text {S1.rms }} \\
{\left[\mathrm{V}_{\text {rms }}\right]}\end{array}$ & $\begin{array}{c}\mathrm{I}_{\mathrm{S} 1 . \mathrm{pk}} \\
{[\mathrm{A}]}\end{array}$ & $\begin{array}{c}\mathrm{I}_{\mathrm{A}, \mathrm{rms}} \\
{\left[\mathrm{A}_{\mathrm{rms}}\right]}\end{array}$ & $\begin{array}{c}\mathrm{I}_{\mathrm{A}, \mathrm{pk}} \\
{[\mathrm{A}]}\end{array}$ & $\begin{array}{c}\mathrm{I}_{\mathrm{T} 2, \mathrm{rms}} \\
{\left[\mathrm{A}_{\mathrm{rms}}\right]}\end{array}$ & $\begin{array}{c}\mathrm{I}_{\mathrm{T} 2, \mathrm{pk}} \\
{[\mathrm{A}]}\end{array}$ \\
\hline 297.5 & 36.3 & 21.1 & 36.4 & 19.2 & $36.81 .2 \mathrm{p} . \mathrm{u}$ \\
$2.5 \mathrm{p} . \mathrm{u}$ & $1.2 \mathrm{p} . \mathrm{u}$ & $1 \mathrm{p} . \mathrm{u}$ & $1.2 \mathrm{p} . \mathrm{u}$ & $0.93 \mathrm{p} . \mathrm{u}$ & \\
\hline
\end{tabular}

\section{Waveforms}

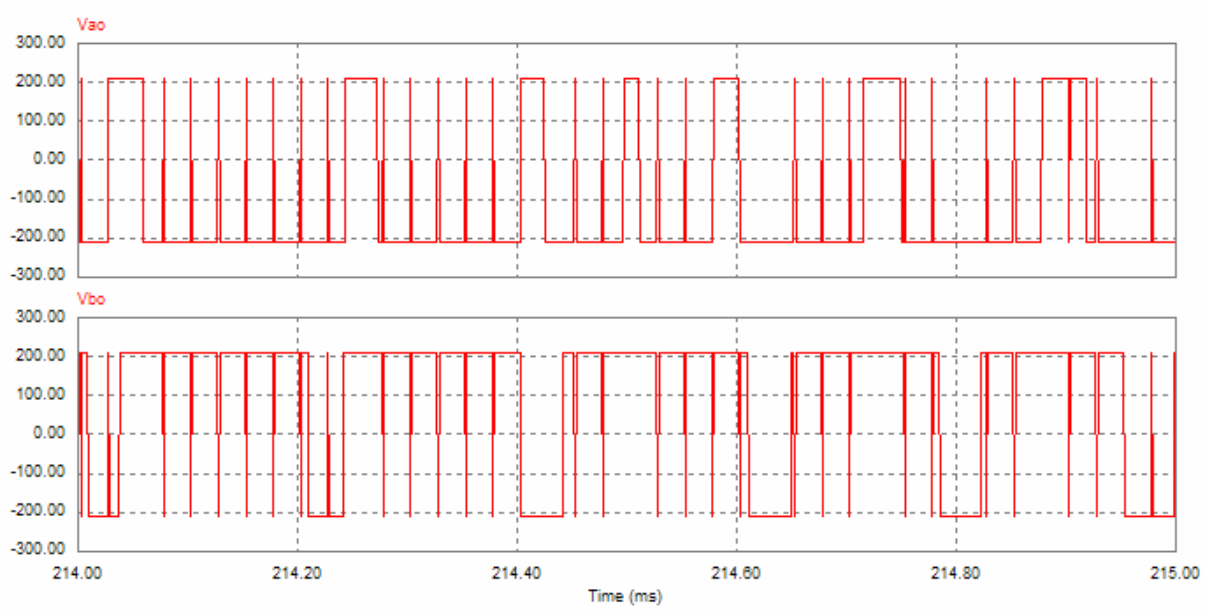

Fig. 13 Unfiltered output voltage of the direct DC to AC converter shown in Fig. 12

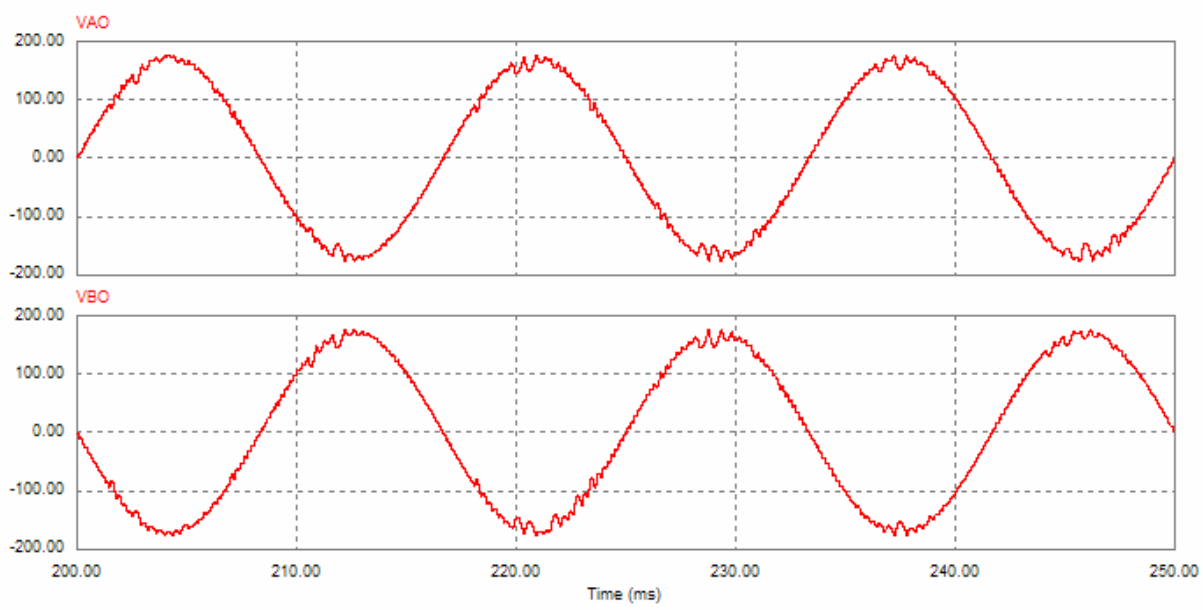

Fig. 14 Single phase $120 \mathrm{~V} / 240 \mathrm{~V}, 6 \mathrm{~Hz}$, 3-wire output voltage of the direct DC to AC 
converter of Fig. 8

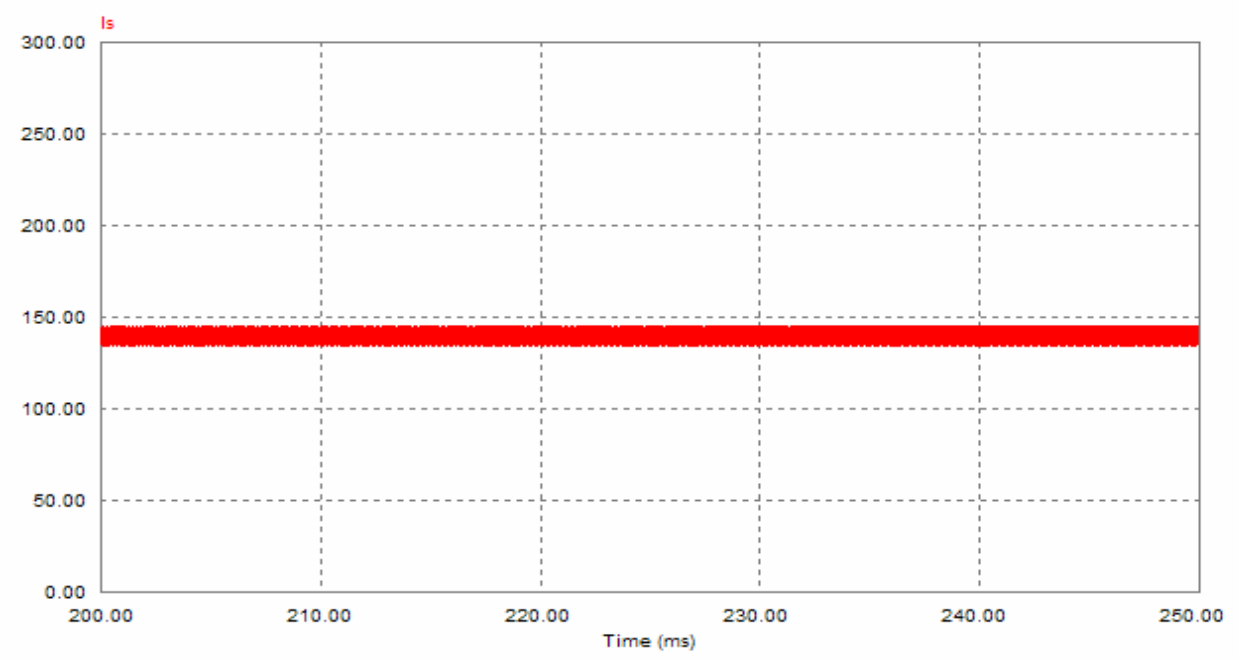

\section{III.3.2 Conclusions:}

Fig. 15 Fuel cell input current waveform

From the results obtained it can be concluded that the topology shown in Fig. 8 and Fig.

12 have several advantages compared to the prior art (conventional DC/DC converter; dc-link followed by DC to AC Inverter):

- This topology provides an intermediate battery energy storage. This allows for the slow dynamic response characteristics of the SOFC.

- Since the direct DC to AC converters (Fig. 8 and Fig. 12) combine the functions of rectifier/dc-link/inverter stages into one stage, a low profile converter construction can be adopted resulting in a higher density package.

- Higher reliability since control of direct DC to AC converter is accomplished by a simple pulse width modulation (PWM) control to regulate the output voltage, while the SOFC power control and battery management functions are performed by the synchronous boost stage. 
- Higher efficiency: The efficiency of the proposed approaches is expected to be greater than $90 \%$ at full load.

- The proposed direct DC to AC converters (Fig. 8 and Fig. 12) are capable of generating 3-phase output by simply altering the PWM gating patterns of the output stage (a change in software).

- TAMU will proposes to pursue the prototype development with the battery energy storage option in Phase-2 and does not anticipate large additional capacitors being necessary to meet the transient energy requirements in view of the slow dynamic performance of the fuel cell.

- TAMU will explore some advanced PWM techniques to minimize $120 \mathrm{~Hz}$ ripple current while simultaneously optimize the Lf and Cf values in Phase-2. 


\section{III.4 Evaluation of Direct DC to AC Converter for three phase AC output (Fig. 3bb}

\section{in Phase-1 SOPO):}

Fig. 3bb in Phase-1 SOPO details a converter concept for generating three phase output suitable for grid interface. In this section an update is provided for the work accomplished so far. Fig. 16 shows a detailed block diagram of a fuel cell power system interfaced to three phase electric grid. The power available from the fuel cell is processed by the converter and supplied to electric grid. During start up the power from the utility is utilized.

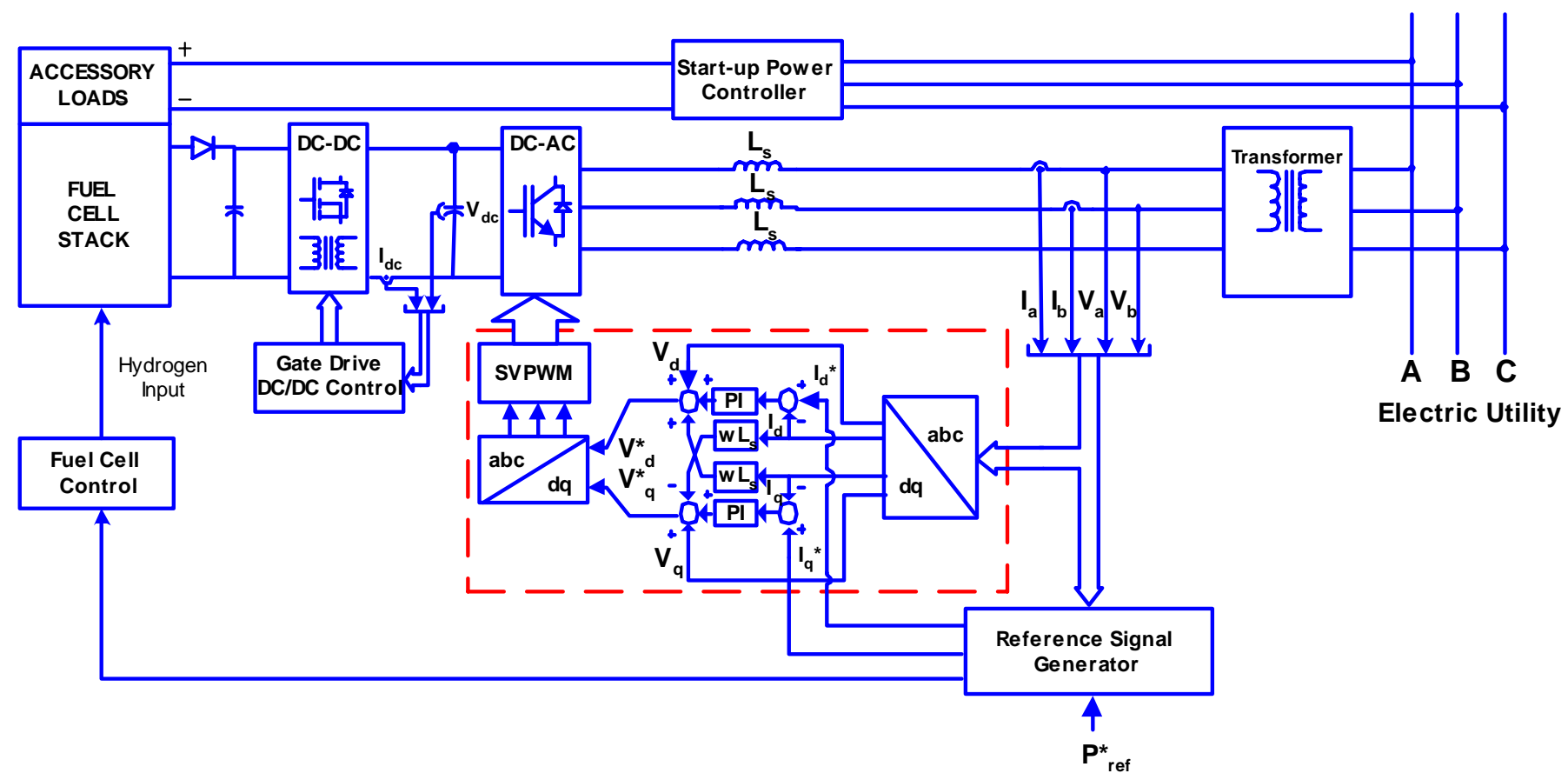

Fig. 16 Fuel cell power conditioner control system for supplying power to the utility (utility interface)

The 3-phase converter concept proposed in Fig. 3bb of Phase-1 SOPO has been modified (while preserving the functionality of direct DC to 3-phase concept) and is shown in Fig. 17. The Fig. 17 concept is an improvement to the topology presented in Fig. 3bb of Phase-1 SOPO. The Fig. 17 topology employs lower number of semiconductor on the secondary side along with a full bride diode rectifier. These 
changes also impose the following limitations: the output power needs to be unity power factor. This is not seen as a problem as the converter will be mainly tied to the grid and its power factor can be kept at unity by controlling the output stage. The power from the SOFC is processed via a high frequency switching four switch MOSFET converter with ZVS features.

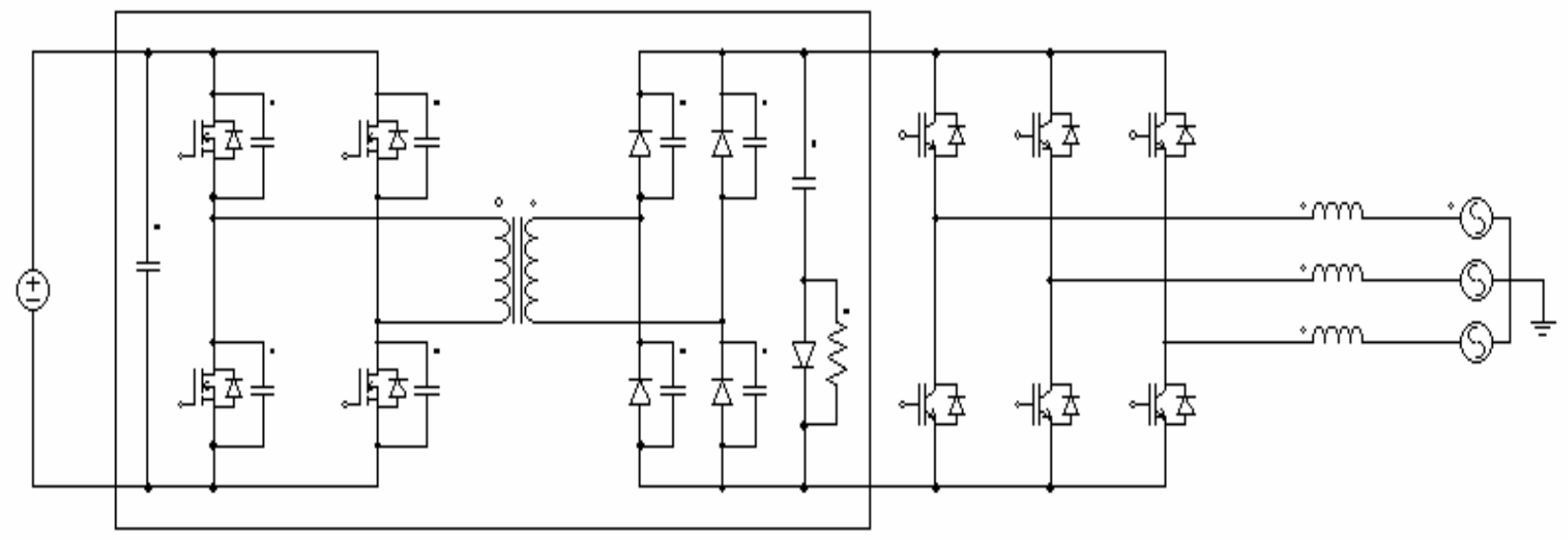
Fuel Cell
Soft switched Full bridge
3 phase
3 phase $208 \mathrm{~V}$
$25 \sim 40 \mathrm{~V}$
$\mathrm{DC} / \mathrm{DC}$ converter
Inverter
reactor utility

Fig. 17 Proposed voltage source type direct DC to AC converter for SOFC (The above converter concept is discussed in Fig. 3bb of Phase-1 SOPO)

The main features of this converter can be summarized as:

- New power conditioner for SOFC

- Near zero turn-on, turn-off switching loss and reverse recovery loss due to ZCS and ZVS operation

- Low power profile and low cost ( No bulky dc-link capacitor)

- Modular design and easy expandability

- Unity power factor utility interface

- Stand-alone operation by synchronous rectifier 
- The output is configurable to three phase or single phase by means of a software change.

\section{ZCS turn-off operation and Snubber design}

While the primary side full bridge converter (with MOSFETs) is commutating, the switching vector of inverter side is zero vector ( $V 0$ or $V 7$ ). This result indicates that during the commutation of primary side, the dc link current is zero because inverter output current freewheels through IGBT switches and anti-parallel diodes. Hence, at this instant, dc link current is reduced to zero, however the primary current keeps conducting due to the leakage inductance of HF transformer. If the energy stored in leakage inductance is eliminated when the commutation of primary side occurs, zero current turn-on and turn-off on the primary side can be guaranteed and switching losses

of the primary side can be significantly reduced. In addition, the secondary rectifying diodes operate under discontinuous current mode and this contributes to the elimination of reverse recovery loss and pertinent EMI problems at the secondary rectifying diodes.

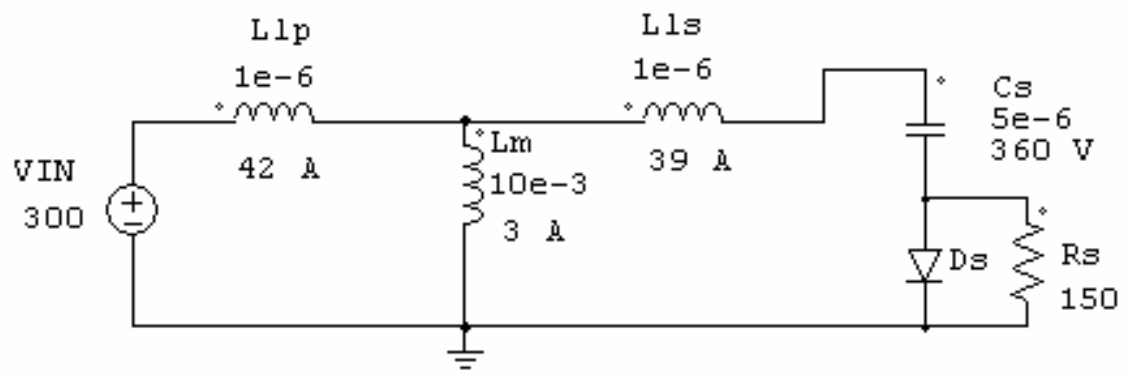

Fig. 18 Equivalent circuit for ZCS operation

In order to remove the stored energy at leakage inductance on time, an RCD snubber is placed in the dc-link. When a switching vector of inverter side changes from active vector $(V 1 \sim V 6)$ to zero vector (VO or V7), inverter becomes separated from the 
MOSFET converter module as shown in Fig. 17. The Fig. 18 shows the proposed soft switched full-bridge dc/dc converter modules during ZCS operation and the primary part is referred to the secondary side. Transformer is replaced by magnetizing inductance and leakage inductances with unity turn ratio. Since the current in leakage inductance is no longer able to conduct to the load through inverter switches, the current is directed to RCD snubber network and dc link voltage is clamped to snubber capacitor voltage $V_{C s}$. The snubber capacitor current $I_{C}$, voltage $V_{C}$ are derived as below.

$$
\begin{aligned}
& I_{C}(t)=I_{O} \cos \left(\omega_{0} t\right)+\frac{V_{I N}-V_{C}\left(0^{+}\right)}{Z_{O}} \sin \left(\omega_{O} t\right) \\
& \text { where } \omega_{o}=\frac{1}{\sqrt{L C}} \quad Z_{o}=\sqrt{\frac{L}{C}} \\
& V_{C}(t)=Z_{o} I_{O} \sin \left(\omega_{O} t\right)+V_{C}\left(0^{+}\right) \cos \left(\omega_{o} t\right)+V_{I N}\left(1-\cos \left(\omega_{O} t\right)\right)
\end{aligned}
$$

The magnetic energy stored in leakage inductance is transferred to the electrostatic energy in capacitor Cs at $T_{\text {reset }}$ by resonance and $T_{\text {reset }}$ is derived by using $I_{C}\left(T_{\text {reset }}\right)=0$ at (8)

$$
T_{\text {reset }}=\sqrt{L C} \tan ^{-1}\left(\frac{Z_{O} I_{O}}{V_{C}\left(0^{+}\right)-V_{I N}}\right)
$$

\section{$\underline{R C D \text { Snubber design consideration }}$}

The design of RCD snubber can be described as follows. Initially, the inverter provides load current and the voltage across the snubber capacitor $C_{S}$ equals $V_{I N}+V_{C}$. At zero vector assuming the dc-link current fall time to be small, the current through $L_{1}$ is essentially $I_{o}$ when dc-link current decreases to zero and the output current then freewheels through the IGBT and anti-parallel diode. At this stage the equivalent circuit is as shown in Fig. 18 where the primary MOSFET switches and the secondary 
rectifying diodes appear as a short circuit since their switching status keeps remaining on. Now the energy stored in the stray inductances gets transferred to the snubber capacitor $C s$ through the diode $D s$ and the voltage increase $\Delta V c$ across the snubber capacitor can be obtained by replacing the pre-charged capacitor with its equivalent circuit as shown in Fig. 19.

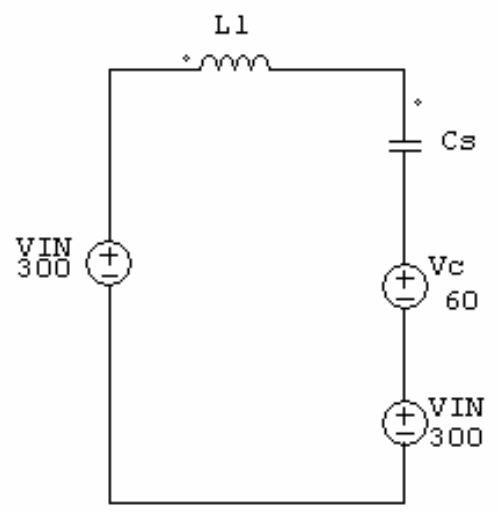

Fig. 19 Equivalent circuit for RCD snubber operation

Using the energy considerations, we obtain

$$
\frac{1}{2} L_{l} I_{O}^{2}=\frac{1}{2} C_{S}\left(V_{C}+\Delta V_{C}\right)^{2}-\frac{1}{2} C_{S} V_{C}^{2}
$$

This equation shows that a large value of $C s$ will minimize the voltage increase $\Delta V c$. Once the current through $L_{1}$ has decreased to zero, it cannot reverse its direction due to the secondary rectifying diodes and the increased voltage on the capacitor keeps constant during zero vector state. When inverter switching vector get changed to active vector and the stored energy is transferred to the load through inverter, the increased voltage $V_{I N}+V_{C}+\Delta V c$ in snubber capacitor decreased to $V_{I N}+V_{C}$ through the snubber resistor $R_{S}$.

Assuming $C_{S}$ to be large relative to switching period and handled energy, the snubber capacitor and snubber network can be replaced by a dc source $V_{C}$ in steady state. 
Since in steady state operation the waveform must repeat from one time period to the next, the integral of the charged and discharged energy on snubber capacitor over one time period must be zero. Therefore, The charged energy from leakage inductance

$$
\frac{1}{2} L_{S} I_{O}^{2}\left(2 f_{S W}\right)=\frac{1}{2} \cdot 2 \mu \mathrm{H} \cdot 39^{2} \cdot 2 \cdot 10 \mathrm{kHz}=30 \mathrm{~W}
$$

is all dissipated at snubber resistor $R_{S}$ in every switching period. Assume maintaining $V_{C}$ to be $60 \mathrm{~V}$ to transfer the leakage inductance energy to snubber capacitor within desired $T_{\text {reset }}$ and resistor value is determined by

$$
R=\frac{V_{C}^{2}}{30 W}=\frac{60^{2}}{30}=120 \Omega
$$

\section{$\underline{\text { ZVS turn-on operation }}$}

In general, ZVS is preferable over ZCS at high switching frequencies. The reason has to do with the internal capacitances of the switch. When the switch turns on at zero current but at a finite voltage, the charge on the internal capacitance is dissipated in the switch and this loss becomes significant at very high switching frequencies. However, no such loss occurs if the switch turns on at a zero voltage and ZVS turn on is chosen along with the above ZCS turn off. The Fig. 20 (a) represents the proposed soft switched fullbridge dc/dc converter modules during ZVS operation and the primary part is referred to the secondary side. Isolation transformer is replaced by magnetizing inductance and leakage inductances with unity turn ratio. The leakage inductances $L_{1 p}$ and $L / s$ are very small compared with the magnetizing inductance $L_{M}$ and $I_{M}$ becomes positive as well as negative during each cycle of operation. Since the dc-link current $I_{0}$ is zero by the aforementioned ZCS operation, the secondary part becomes separated from the circuit operation and Fig. 20 (b) shows the equivalent circuit of the remaining part. 


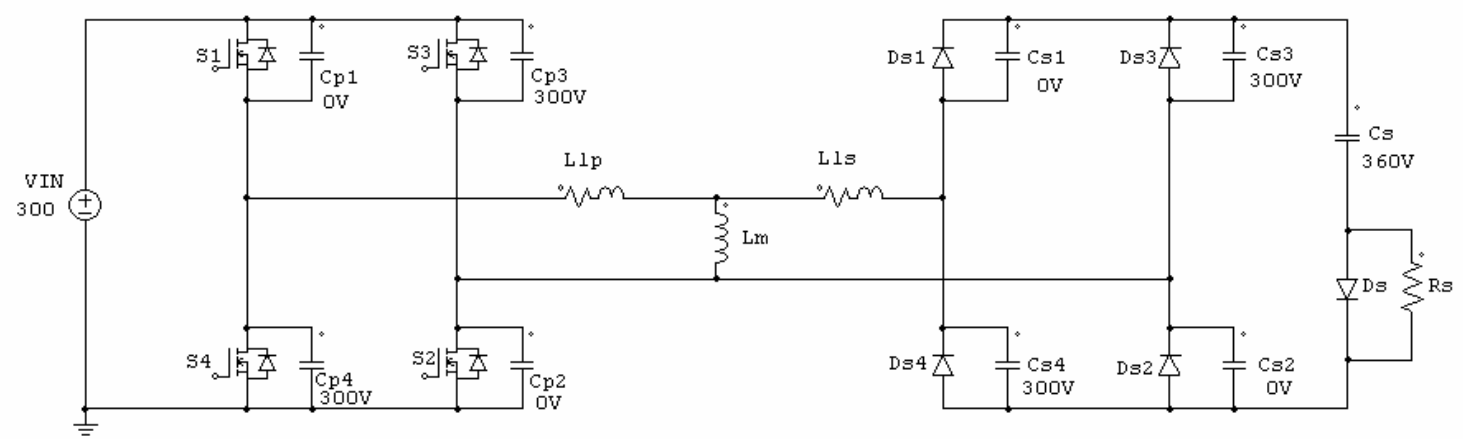

(a)

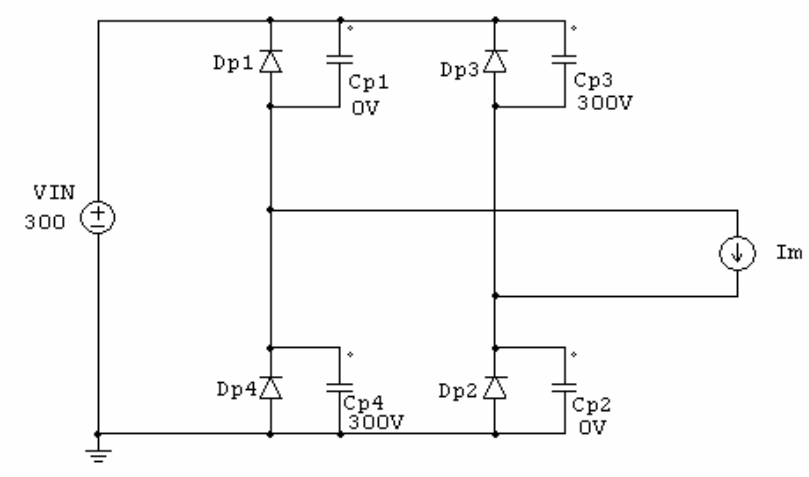

(b)

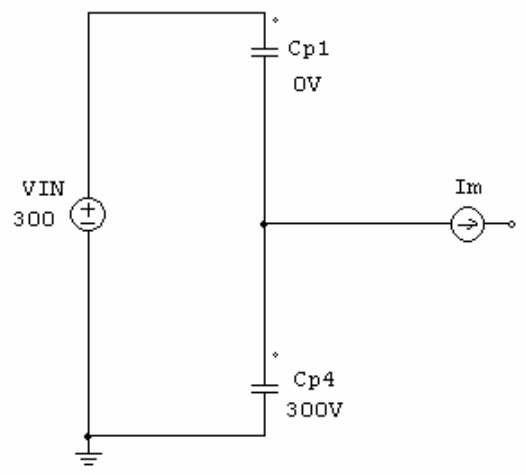

(c)

Fig. 20 (a) Soft switched full-bridge dc/dc converter modules during ZVS operation (b) Equivalent circuit of the primary side (c) the simplified model during ZVS

Since ZVS operation at $S 1, S 4$ arm is the same as $S 2, S 3$ arm, the operation of $S 1, S 4$ arm are explained for simplicity. Initially, $S 1$ is conducting a positive $I_{M}$. At switching transition, $S 1$ is turned off at zero voltage because of $C_{p 1}$ in Fig. 20 (b) ; the voltage across $S 1$ builds up slowly compared with its switching time. With $S 4$ off and $S 1$ just off, the circuit can be redrawn as in Fig. 20 (c), where magnetizing inductance is simplified as current source. This allows the assumption that voltage across $S 1, S 2$ are charged/ discharged linearly, respectively during the blanking time interval where both the switches are off. During the transition interval, the magnitude of $d v / d t$ across both the capacitors is same, therefore, $I_{M} / 2$ flows through each of the capacitors during this 
interval since $C_{p 1}=C_{p 4}$. In this design, discrete $2 \mathrm{nF}$ capacitors are added to MOSFET switches and the required charging/discharging time is

$$
{ }_{Z} \text { ZVS }=\frac{2 C_{p} V_{I N}}{I_{m}}=\frac{2 \cdot 2 n F \cdot 300 V}{2.5 A}=0.48 \mu \mathrm{sec}
$$

Therefore, the blanking time is chosen as 1 usec $>t_{z v s}$. During charge/discharge process, magnetizing current provides the constant charging/discharging current to primary side FB converter through leakage inductance shown as Fig. 20 (b). Transition time is constant regardless of the magnitude of load current because the process is based on the peak value of magnetizing constant and the peak value of magnetizing constant is determined by the magnitude of input voltage. Also coming active switches are turn on under ZCS condition.

\section{Inverter for Utility Interface:}

This inverter part (Fig. 17) is the same as the traditional three phase inverter without DC capacitors. The DC link voltage varies from $320 \mathrm{~V}$ to $462 \mathrm{~V}$ due to the V-I characteristic of used fuel cells (here, SOFC) but some amount of voltage variation at dc-link is permissible because voltage variation occurs slowly and is compensated easily by the synchronous frame current regulator. Conventional voltage source inverter structure ( $T 1$

$\sim$ T6) is chosen as varying dc-link to three-phase ac power conversion stage and two methods are used to allow the operation of the proposed inverter over a range of utility voltages with very low current distortion and unity displacement factor. First, the synchronous reference-frame $d$ and $q$ current regulators are adopted with the feedforward compensation of speed voltage term to eliminate the cross coupling between the $d$ and $q$ phases and it allows the reduction of the current control loops to first-order plants and improved their tracking capability. Second, for better dc-link voltage 
utilization and the operation of the current regulator within linear range, space vector PWM method is adopted. Fig. 21 (a) shows the three phase inverter connected to utility through interface reactor and the whole $d c / d c$ converter aforementioned is variable $d c$ voltage source. Fig. 21 (b) illustrates the block diagram of synchronous reference-frame $d$ and $q$ current regulators.

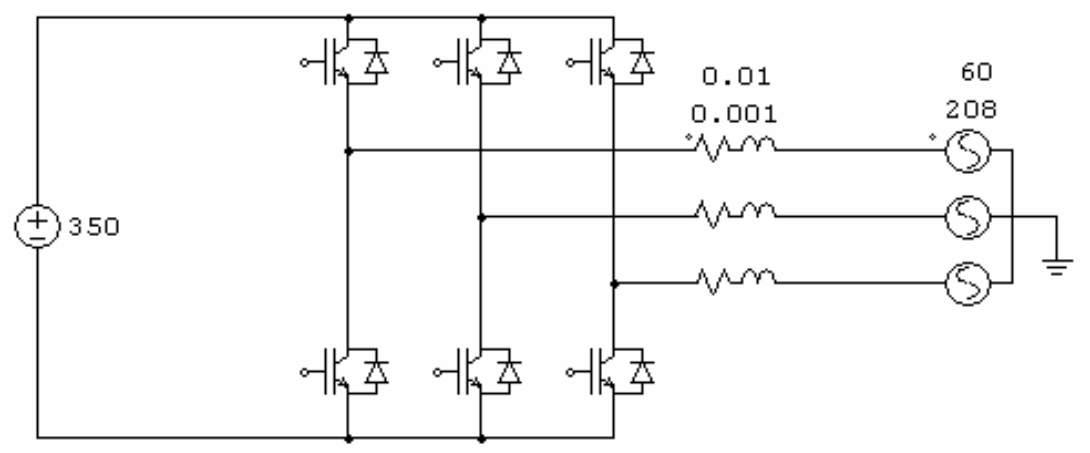

(a)

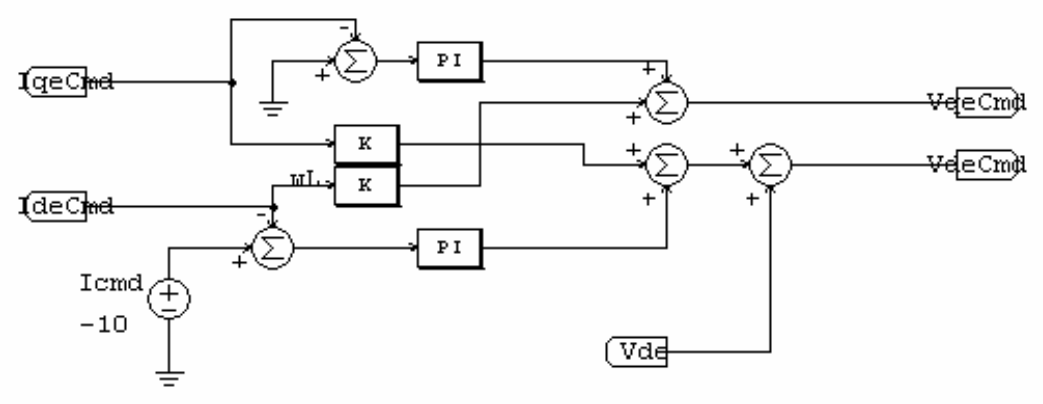

(b)

Fig. 21 (a) Utility interface inverter (b) synchronous PI current controller

\section{$\underline{\text { Transformer design consideration }}$}

This part deals with the proper selection of dc-link voltage, takes into account the utility voltage fluctuation and widely varying fuel cell output voltage and derives a minimum turn-ratio $n$ of HF transformer to accommodate these issues. The secondary side inverter along with well-designed current controller and fixed frequency utility can be modeled as two independent ac voltage sources connected through inductor $L_{F}$, which 
acts as the load between utility voltage $U$ and converter output voltage $V$ shown in Fig. 22 (a). The direction of power flow between these two sources depends on their magnitudes $\left(U_{m}\right.$ and $\left.V_{o m}\right)$ and phase angles ( $\theta_{\cup}$ and $\left.\theta_{V}\right)$. The voltage and current relationships of the utility interactive inverter can be analyzed using the phasor diagram in Fig. 22 (b). Neglecting the resistor drop in the line and assuming unity displacement factor operation (synchronous frame reactive current $I_{d}{ }^{e}=0$ ), the amplitude of the converter output voltage $V_{\text {om }}$ can be calculated as

$$
V_{o m}=\sqrt{U_{m}^{2}+\left(\omega_{o} L_{F} I_{q}^{e}\right)^{2}}
$$

where $f_{o} \quad$ utility frequency

$$
\begin{array}{ll}
\omega_{o} & 2 \pi f_{o} \\
I_{q}^{e} & \text { active component current }
\end{array}
$$

In order to avoid saturation in a space vector pulse width modulator and considering a maximum modulation index of 0.95 , the peak phase voltage $V_{\text {om }}$ must be

$$
V_{o m} \leq \frac{V_{d c}}{\sqrt{3}} \cdot 0.95 \quad \text { where } \quad V_{d c}=n V_{I N}
$$

Combining (16) and (17), the boundary condition for PWM saturation can be given as a relationship between dc-link voltage $V_{d c}$ and utility voltage $U_{m}$ and a required turn-ratio $n$ of $\mathrm{HF}$ transformer is derived as

$$
n=\frac{N_{S}}{N_{p}} \geq \frac{\sqrt{3} \cdot \sqrt{U_{m}{ }^{2}+\left(\omega_{0} L_{F} I_{q}^{e}\right)^{2}}}{V_{I N} \cdot 0.95}
$$




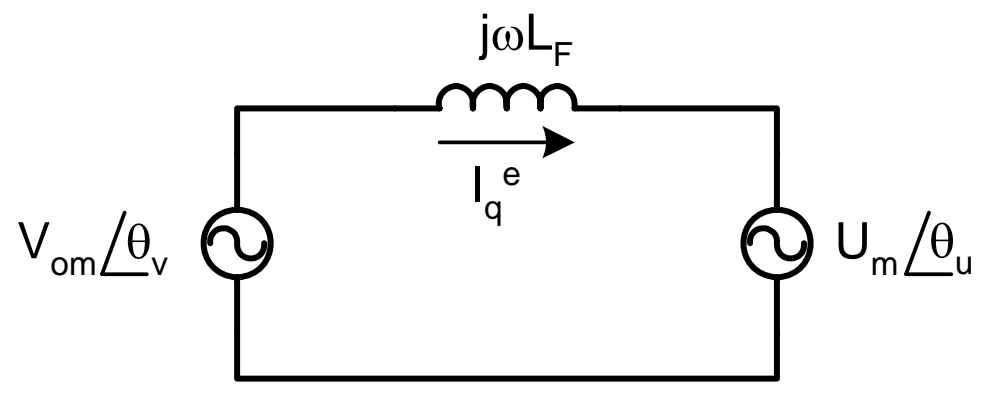

(a)

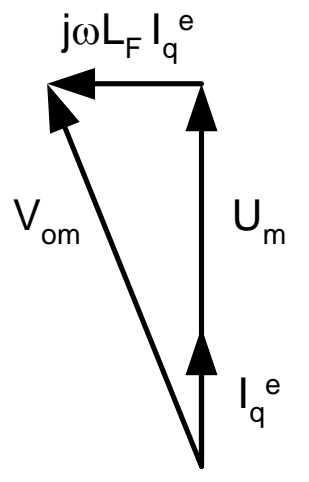

(b)

Fig. 22 (a) Equivalent circuit model (b) phasor diagram when displacement factor is 1.0

\section{Results:}

Fig. 23 shows the simulation result for the proposed ZCS and ZVS operation. At t1, utility interface inverter switching status is changed to zero vector and $I_{d c 2}$ becomes disappeared as shown in first-row waveform. Meanwhile, $I_{d c 1}$ keeps conducting through transformer leakage inductance and transfer its trapped magnetic energy to snubber capacitor $C_{S}$ by $\mathrm{t} 2$. At $\mathrm{t} 1 \sim \mathrm{t} 2$, dc link voltage $V_{d c 2}$ is clamped by snubber capacitor voltage $V_{d c 1}$ and this interval corresponds to $T_{\text {reset }}$ at (3). After t2, $I_{d c 1}$ is just magnetizing current for transformer and is used for energy source for ZVS at primary side dc/dc converter. The fourth-row indicates the magnetizing current $I_{M}$ and keeps constant in this short switching transition. At $\mathrm{t} 3, \mathrm{dc} / \mathrm{dc}$ converter changes the polarity of its square wave output and fifth-row represents ZVS occurs at a MOSFET half bridge arm. The interval $\mathrm{t} 3 \sim \mathrm{t} 4$ corresponds to $t_{z v s}$ at (6) and blanking time of MOSFET half bridge arm is chosen greater than $t_{z v s}$. Since the dc/dc converter switching occurs at almost zero current and zero voltage, its switching losses are nearly eliminated and pertinent EMI is drastically reduced. At t5, utility interface inverter switching status goes back to active 
vector and dc link current $I_{d c 1}, I_{d c 2}$ at primary side and secondary side, respectively increase to supply the required load current. At this instant, there is a voltage dip in the dc-link voltage $V_{d c 1}$ as shown in the third-row and this interval is a current build-up time through leakage inductance.

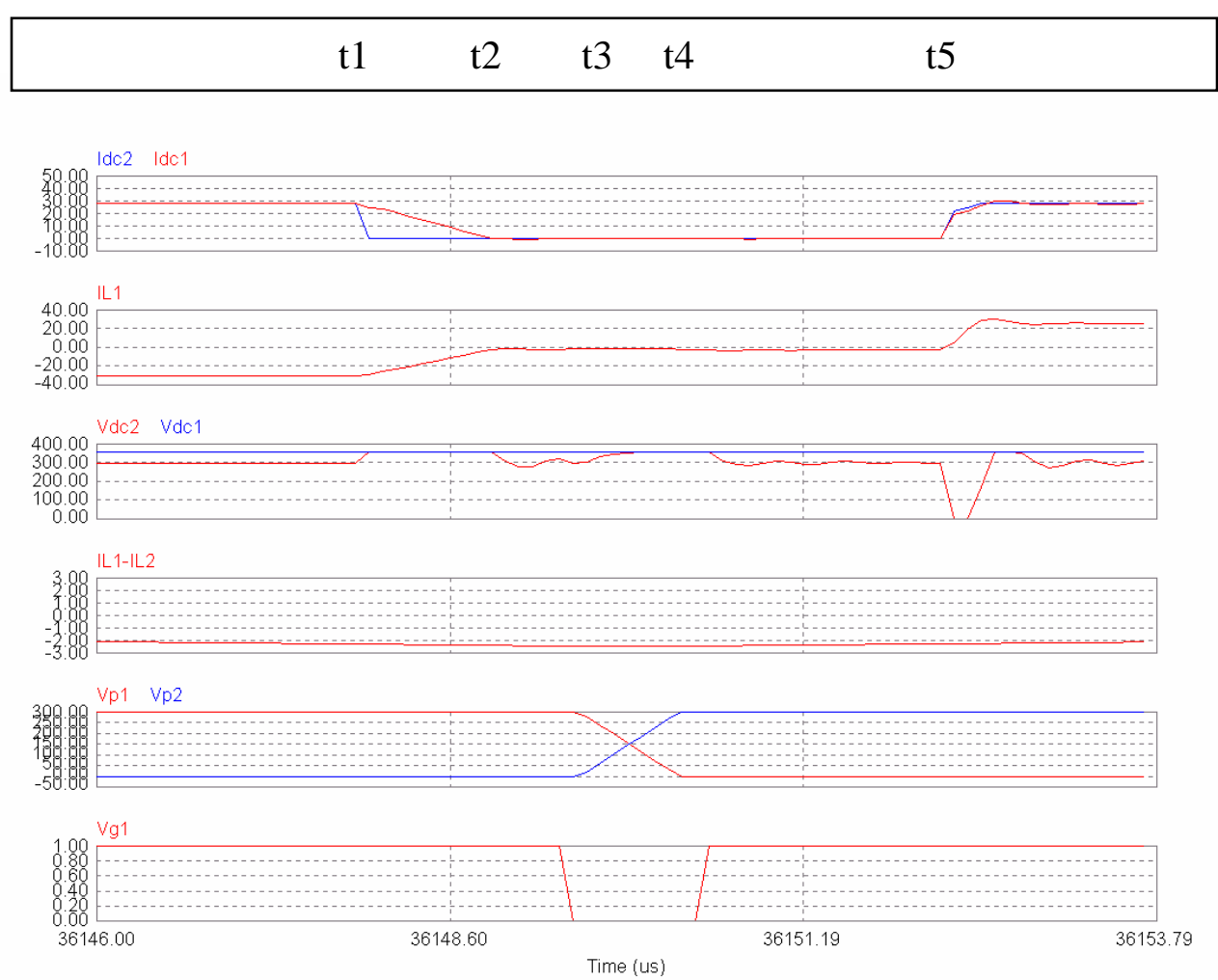

Fig 23. ZCS and ZVS operation

Fig. 24 shows the waveforms at dc-link side and represents proposed RCD snubber operation. Utility interface inverter and dc/dc converter operates at $10 \mathrm{kHz}$ switching and synchronized each other to guarantee the proposed ZCS and ZVS. In other words, switching transition of square wave dc/dc converter occurs at zero vector interval of utility interface inverter. $I_{11}$ is the primary current through leakage inductance and reverses its polarity in every 50 usec. $I_{/ 1}$ is transformed through transformer, rectified by secondary rectifying diode and becomes $I_{d c 2}$ as shown in first-row. It should be noticed 
that $I_{d c 2}$ is the same as dc-link current generated by three phase inverter and it means high frequency current pulse train is provided by fuel cell through transformer directly without any reactive energy reservoir. Third-row shows the charging current to snubber capacitor and its current shape and charging time is determined by RCD snubber parameter design. Fourth-row shows the magnetizing current of transformer.

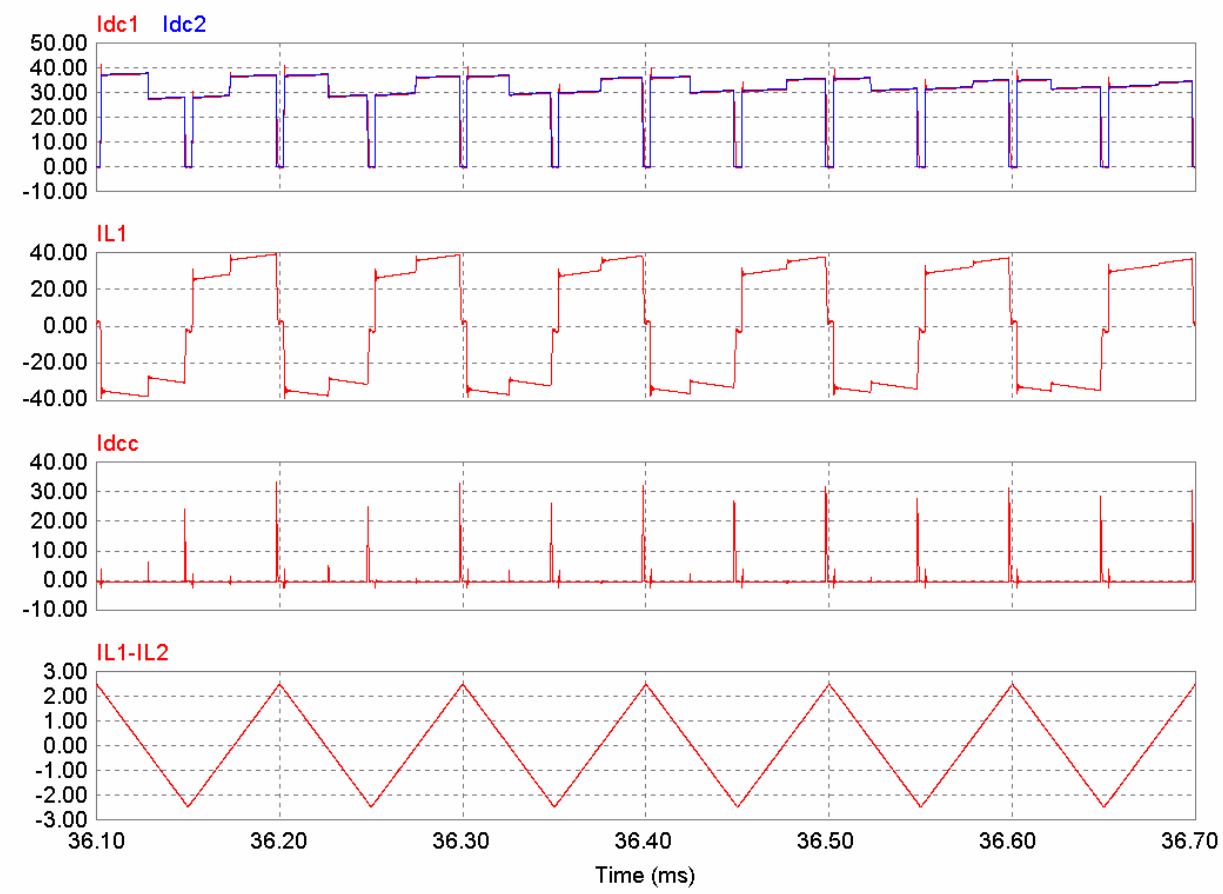

Fig. 24 waveform at dc-link and RCD snubber operation

Fig. 25 illustrates the waveforms for ZCS and ZVS operation at primary side MOSFETS and secondary side diodes when $5 \mathrm{~kW}, 0.98$ power factored $\mathrm{R}-\mathrm{L}$ load is connected to the proposed power conditioner. When the inverter part goes to zero state, the load current at utility side freewheels through IGBTs and anti-parallel diodes connected to same dclink rail and the load current trapped at leakage inductance of transformer flows into snubber capacitor. The energy transferred to snubber capacitor is dissipated by snubber resistor and transferred to output during the active vector interval of inverter 
part. After removing of the energy stored at leakage inductance, dc/dc converter changes the output polarity. By proposed ZVS action, the stray capacitors at MOSFETS and diodes are charged/ discharged in a linear rate by the magnetizing current. The waveforms at drain-source voltage of MOSFET at half-bridge and anode-cathode voltage of diode shows ZVS turn on occurs at both sides of transformer.

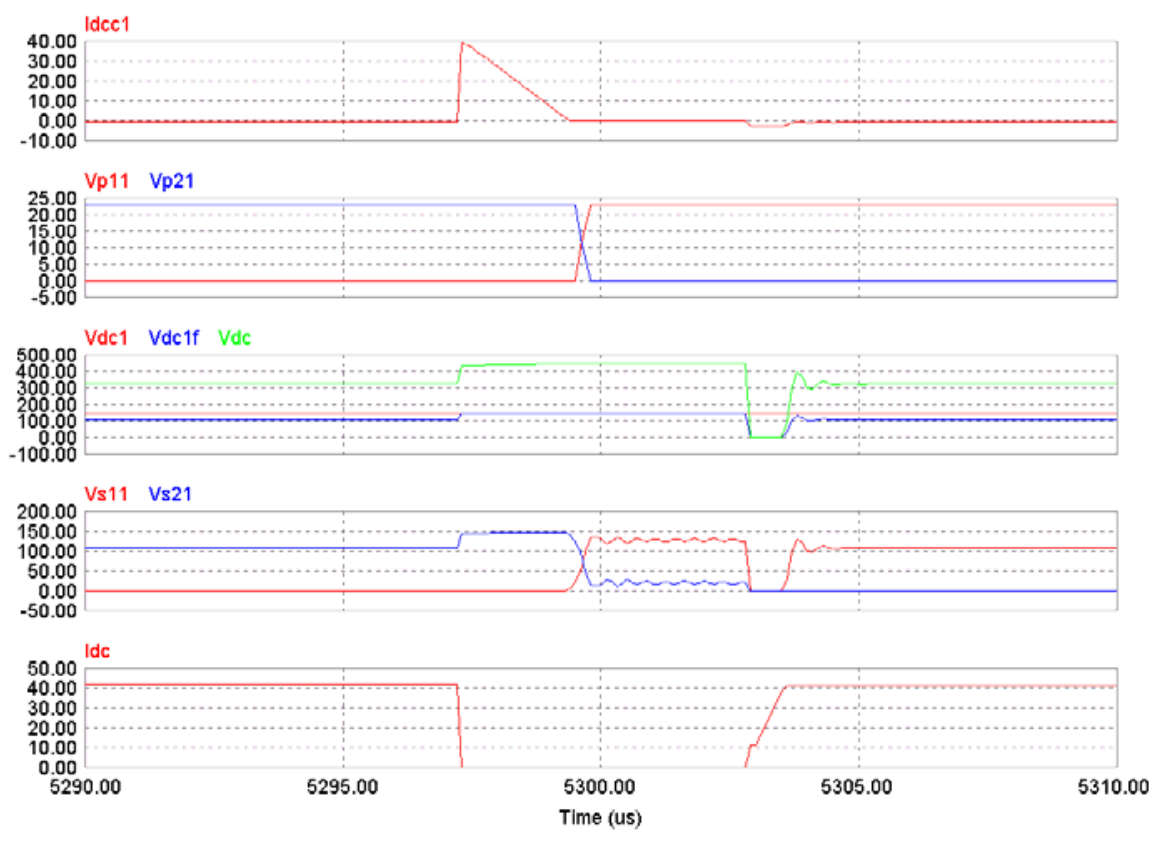

Fig. 25 the waveforms for ZCS and ZVS operation at $10 \mathrm{~kW} \mathrm{R-L} \mathrm{load}$

\section{III.4.1 Conclusion}

As seen from the above results, the proposed converter (Fig. 17) is most suitable for interfacing to grid at unity power factor. The approach also offers full ZVS and ZCS operation of the switches and high conversion efficiency can be realized. These results will be fully discussed with SECA industrial partner DELPHI for their $25 \mathrm{~kW}$ utility interactive 3-phase SOFC unit. Since the SECA industrial partner DELPHI's interest is mainly on 5kW 1-phase SOFC unit at the present time, it is concluded that this converter development will not be a part of TAMU Phase-2 application. 


\section{References:}

[1] S. Kim, S. K. Sul and T. A. Lipo, "AC/AC power conversion based on matrix converter topology with unidirectional switches", IEEE Trans. IA, Vol. 36, No. 1, pp. 139-145, 2000

[2] V. Kaura and V. Blasko, "Operation of a Voltage Source Converter at Increased Utility Voltage", IEEE Trans. PE, vol. 12, No. 1, pp. 132-137, January, 1997

[3] N. Mohan T. M. Undeland and W. P. Robbins, "Power Electronics : Converters, Applications, and Design " $3^{\text {rd }}$ Edition 


\title{
Development of High Frequency
} Link Direct DC to AC Converters for Solid Oxide Fuel Cells (SOFC)

\author{
Dr. Prasad Enjeti \\ Power Electronics Laboratory \\ Department of Electrical Engineering \\ Texas A\&M University \\ College Station, TX - 77843
}

SECA Industrial Partner: Delphi-Auto

\section{Fuel Cell Power Conditioning Stage:} Block diagram (dedicated loads)

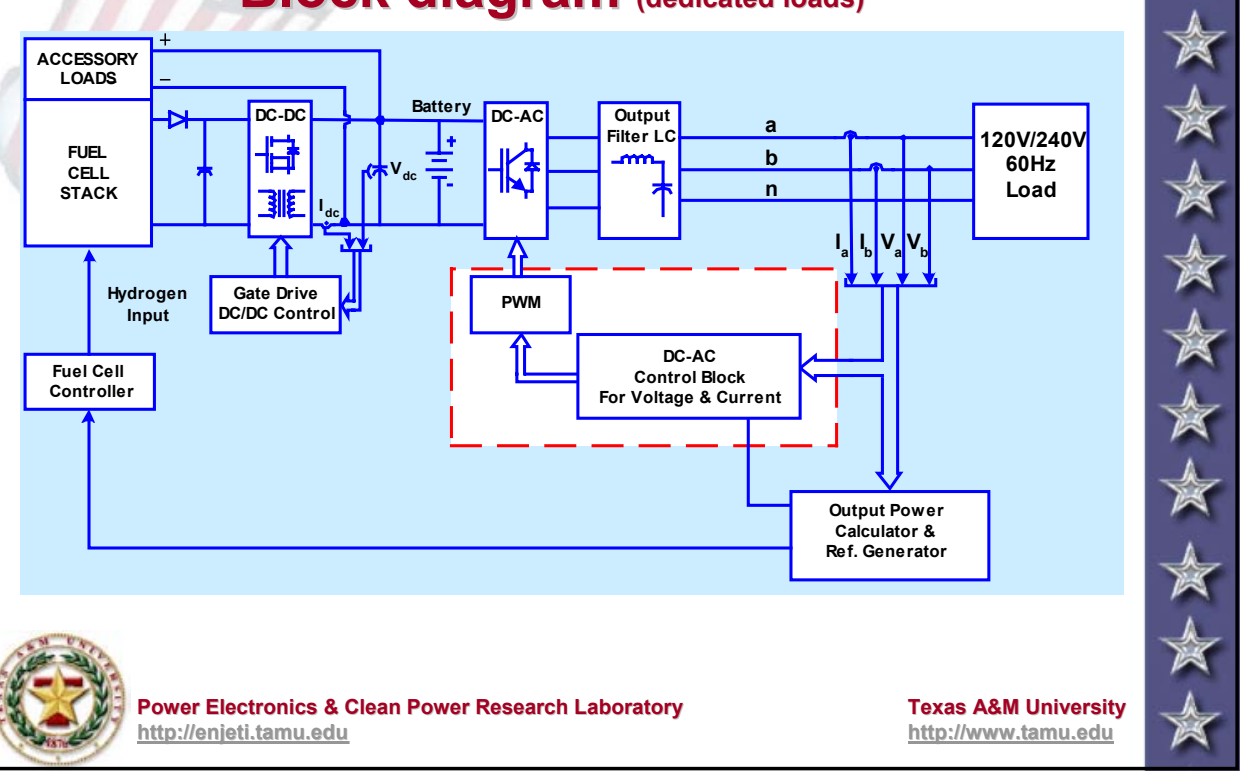




\section{Fuel Cell Power Conditioning Stage: Block diagram (connected to utility)}

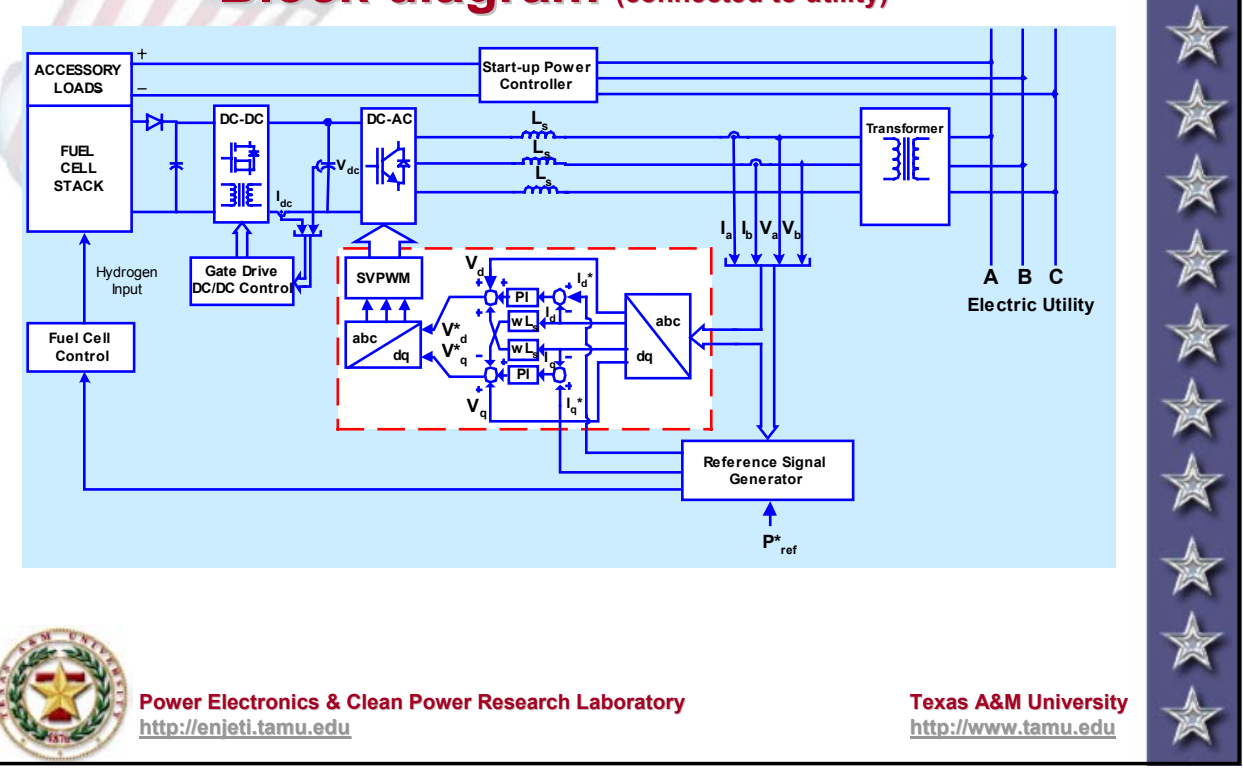

\section{High Frequency Link Direct DC to AC Converters for SOFC}

This project proposes to design and develop high frequency link direct DC to AC converters to improve performance, optimize the size, cost, weight and volume of the DC to AC converter in SOFC systems

$\diamond$ The proposed topologies employ a high frequency link, direct DC to AC conversion approach. The direct DC to AC conversion approach operates without an intermediate dc-link stage

- The absence of the dc-link, results in the elimination of bulky, aluminum electrolytic capacitors, which could result in lower weight/volume/size and cost of the power electronic converter 


\section{R\&D Objectives \& Approach}

* The primary objective is to realize cost effective fuel cell converter, which operates under a wide input voltage range, and output load swings with high efficiency and improved reliability

* Employ state of the art power electronic devices \& configure two unique topologies to achieve direct conversion of DC power (24-48V) available from a SOFC to AC power $(120 / 240 \mathrm{~V}, 60 \mathrm{~Hz})$ suitable for utility interface and powering stand alone loads

* Investigate direct DC to AC conversion

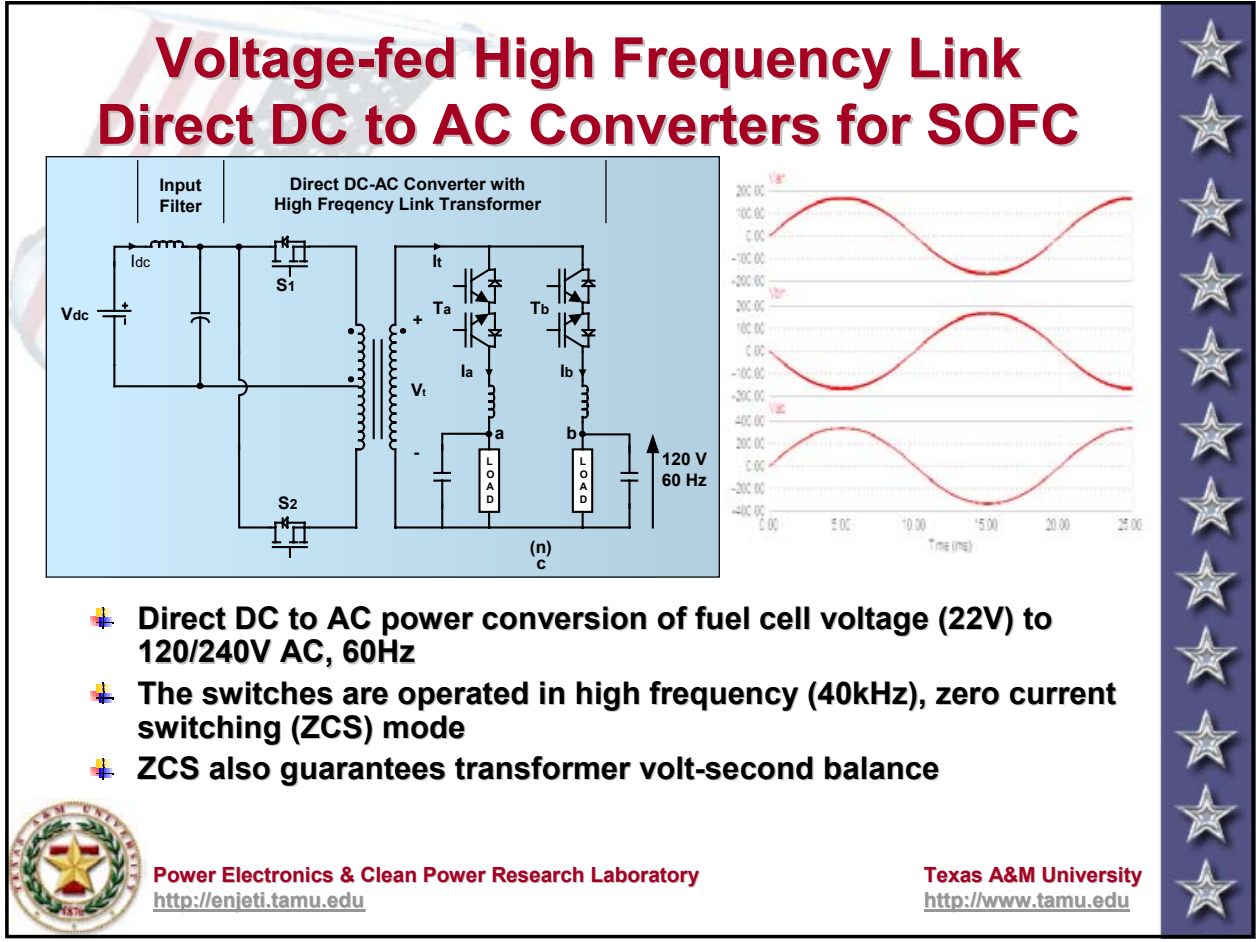




\section{Current-fed High Frequency Link Direct DC to AC Converters for SOFC}

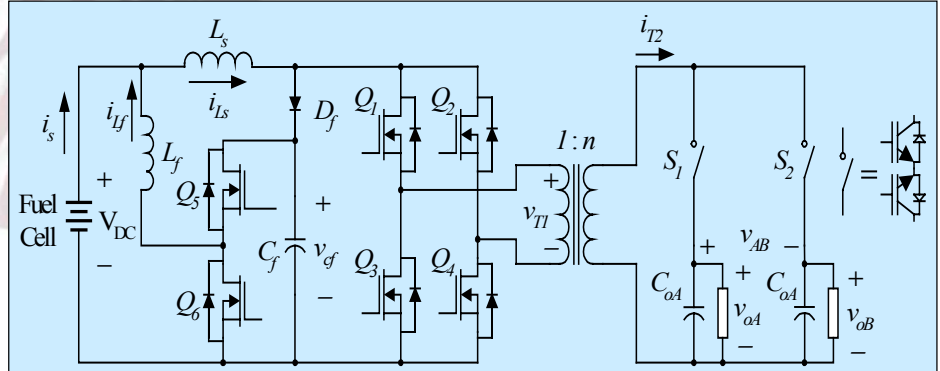

* Current-fed direct DC to AC power conversion of fuel cell voltage (22V) to $120 / 240 \mathrm{~V} \mathrm{AC}, 60 \mathrm{~Hz}$

+ Consists of full-bridge inverter Q1-Q4, HF transformer, simplified AC-AC converter

* The switches Q5, Q6 (are optional) provide input ripple current $(120 \mathrm{~Hz})$ cancellation

\section{Current-fed High Frequency Link Direct DC to AC Converters for SOFC}

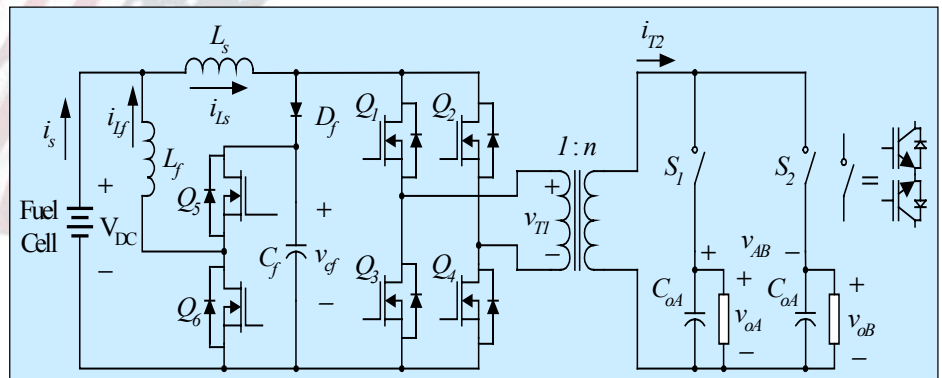

- Full-bridge inverter offers lower switch stress, simple voltage clamping and transformer flux balance

+ The switches Q5, Q6, Lf (optional components) provide active filtering function: i.e. cancellation of fuel cell input ripple current

* The converter has three operating modes 

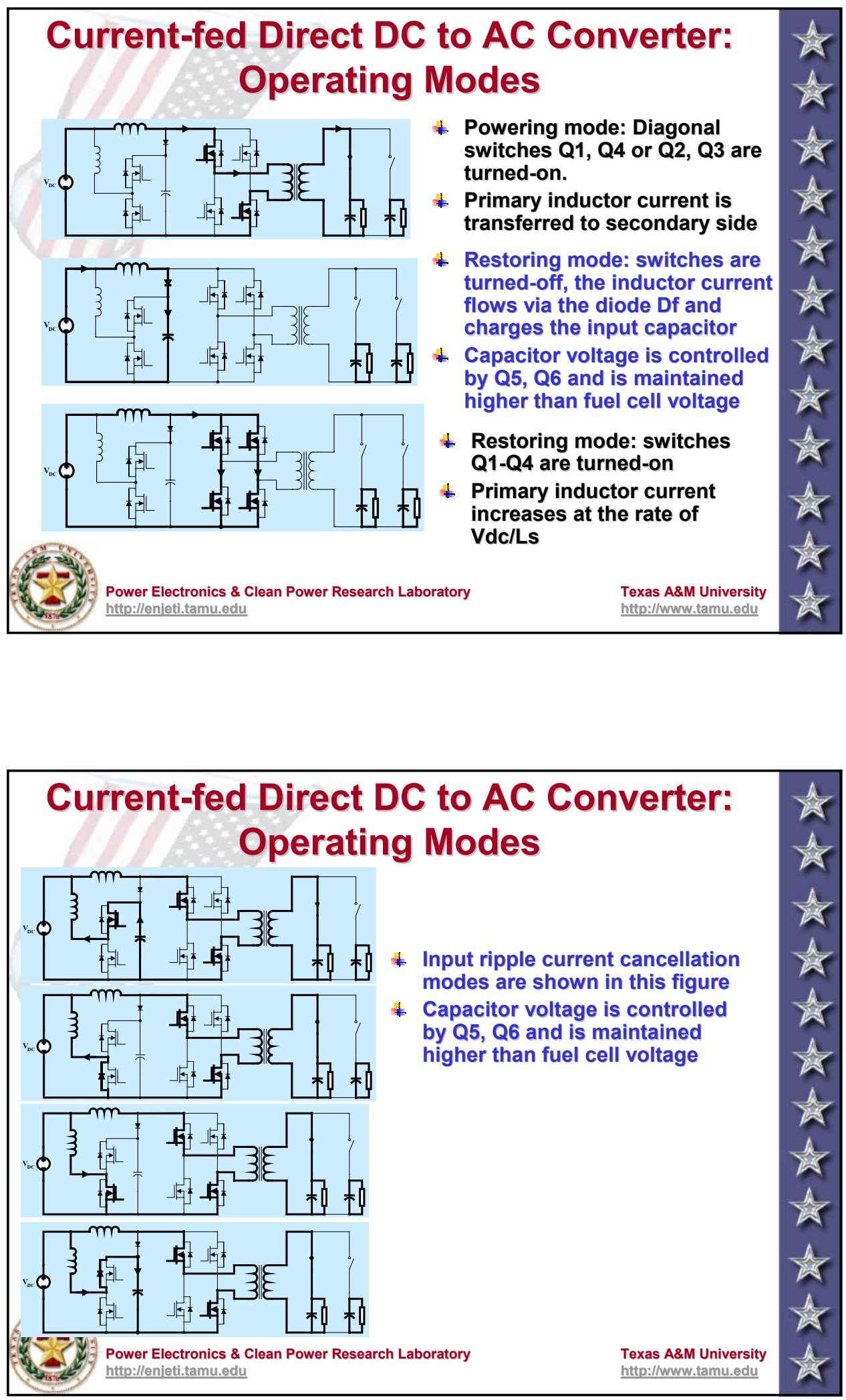

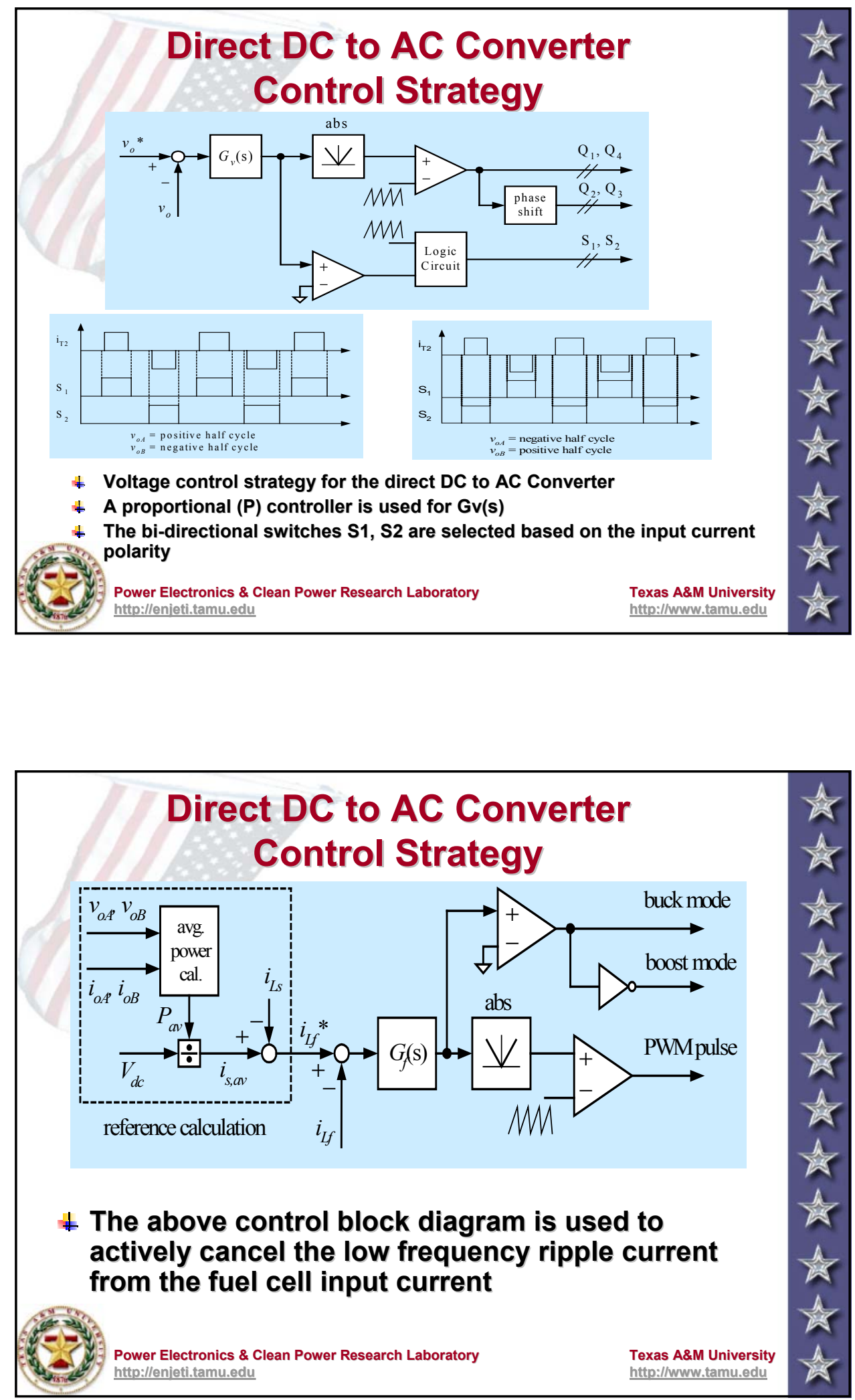


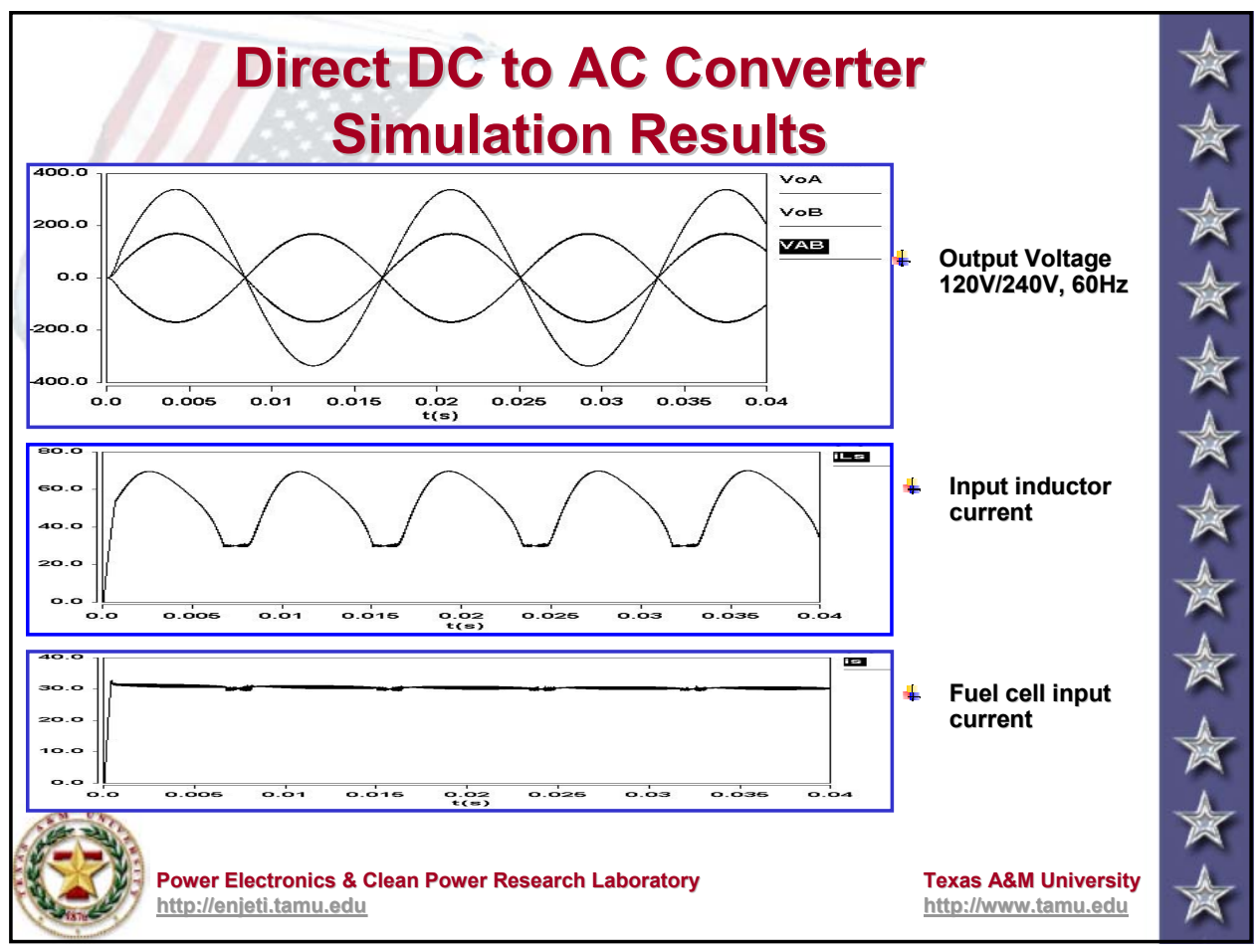

\section{Activities for the Next 6-12 months}

* Task \# 1: Design: A detailed design of the proposed direct DC to AC converters will be completed: high frequency transformer design, component ratings, protection circuitry, hardware layout will be completed followed by a comprehensive simulation of the $\mathrm{FCl}$ systems. The design will be optimized to handle wide input voltage range and output load swings. Completed

* Task \# 2: Evaluation of Fuel Cell Ripple Current \& Energy Storage: A trade study will be initiated to study the performance of various types of input filter designs

+ Task \# 3: Hardware Construction \& Testing: Hardware components will be procured for the development of the proposed converters and tested with DSP control in open loop

* Task \# 4: Testing \& Verification: The proposed converters will undergo linear \& nonlinear load testing on a SOFC fuel cell simulator. These tests will be conducted in coordination with SECA Industrial partner: Delphi-Auto 


\section{SOFC Fuel Cell Simulator Development}

to assist in testing/validation

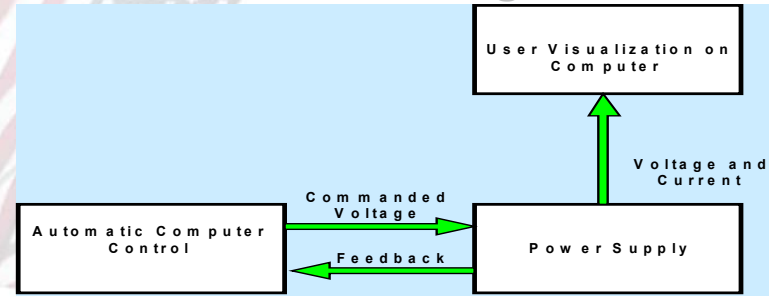

* The purpose of the fuel cell simulator is to enable testing and validation of power conditioning module performance under various loading conditions

* A programmable DC power supply $(0-55 \mathrm{~V}, 10 \mathrm{~kW})$ is controlled via Labview to emulate V-I characteristics of a SOFC

* Labview is employed for SOFC V-I curve fitting and emulation 


\section{A Current-Fed High Frequency Link Direct DC/AC Converter with Active Harmonic Filter for Fuel Cell Applications}

\section{Introduction}

The fuel cell is a highly promising alternative for environmentally friendly renewable energy generation due to its efficiency, modularity, and cleanness. One of its applications for medium power is the residential power system, where an isolated low cost $\mathrm{DC} / \mathrm{AC}$ converter is required. Researches on this topic have been presented in recent years [1]-[4].

The high frequency (HF) link power conversion technique is attractive for this application because of its compact $\mathrm{HF}$ transformer replacing the bulky $60 \mathrm{~Hz}$ transformer [4]. There are two types of HF link DC/AC converters; the DC link and AC link types. The DC link type DC/AC converter can be easily constructed, but the energy storage element makes it bulky and its several conversion steps make the efficiency low. The AC link type consists of a primary side inverter, a secondary side cycloconverter, and a HF transformer. Using this configuration, a compact direct DC/AC converter can be constructed without the DC link capacitor, which provides the high conversion efficiency due to the reduced conversion step [7].

Since the residential power system needs two split single phase output voltages of $120 \mathrm{~V}_{\text {rms }}$ from the low $48 \mathrm{~V}$ DC source, a boost type converter or a high turn ratio of the transformer is required [9]. A current-fed DC/AC converter is known as an effective solution for the power conversion from the low to high voltages because it can operate in the buck and boost modes, and provides easy balancing of transformer. Moreover, a current-fed converter requires less size of the input filter because the primary inductor is placed in the input side, while the voltage-fed converter needs a large capacitor to protect the fuel cell from the input current ripple [3], [4]. However, this current-fed converter still can not the input harmonic current of $120 \mathrm{~Hz}$ that is inevitable in the single phase inverter with an output frequency of $60 \mathrm{~Hz}$ and may impose severe effects to the performance and durability of the fuel cell [5].

In order to overcome this problem, a low cost current-fed $\mathrm{HF}$ DC/AC converter with an active harmonic filter is proposed in this paper. The proposed converter consists of the current-fed HF link DC/AC converter and active harmonic filter using the electrolytic capacitor and two MOSFET switches. The current-fed HF link DC/AC converter generates two split single phase AC outputs from the fuel cell powered DC source in a single stage. The active harmonic filter makes the compensation current eliminating the input harmonic current of $120 \mathrm{~Hz}$. In this summary, the operation and control of the proposed DC/AC converter are presented and the simulation results are provided to verify the usefulness of the proposed scheme. The experiment is being preceded for the prototype converter and the results will be provided in the final paper.

\section{Current-Fed High Frequency Link DC/AC Converter}

Fig. 1 shows the proposed current-fed HF link DC/AC converter with an active harmonic filter for fuel cell applications. This consists of the full-bridge current-fed HF link DC/AC converter and active harmonic filter. The fullbridge inverter and cycloconverter generate the split phase AC outputs from the fuel cell powered DC source. The active harmonic filter makes the compensation current eliminating the harmonic current of $120 \mathrm{~Hz}$ that appears in the input side.

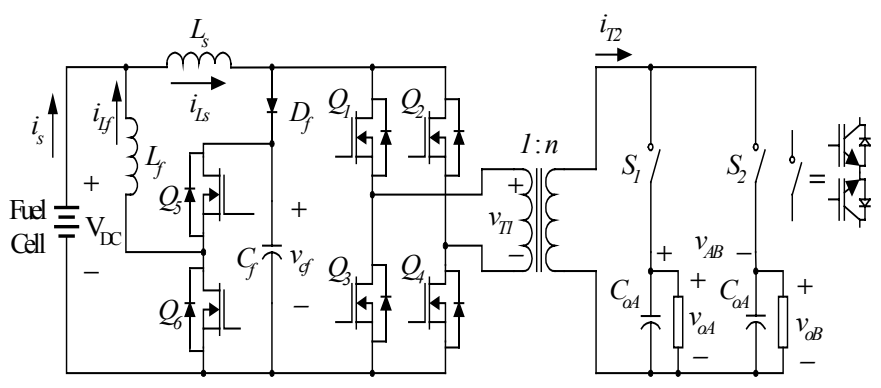

Fig.1 Proposed current-fed HF link DC/AC converter. 
The proposed current-fed HF link DC/AC converter has a single stage without the buck regulation stage, which consists of the primary inductor $\left(L_{s}\right)$, full-bridge inverter $\left(Q_{1}-Q_{4}\right)$, HF transformer, two bi-directional switches $\left(S_{l}\right.$ and $\left.S_{2}\right)$, and output capacitors $\left(C_{O A}\right.$ and $\left.C_{O B}\right)$. The diode $D_{f}$ and capacitor $C_{f}$ in the active filter are used for the voltage clamping in the main HF link inverter operation without the additional claming circuits. The full-bridge configuration offers the low switch stress, simple voltage clamping, and simple structure and easy balancing of the HF transformer as compared with the push-pull configuration. Moreover, the secondary side has the simplest structure with only two bidirectional switches and capacitors.

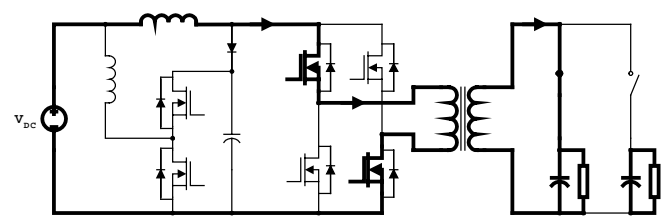

(a)

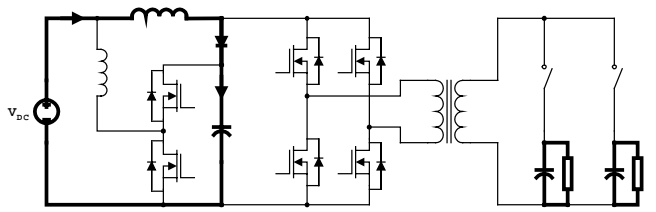

(b)

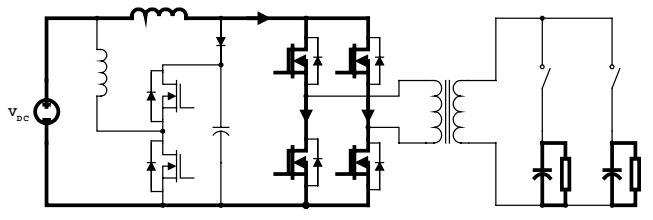

(c)

Fig. 2 Operating modes of current-fed HF link DC/AC converter. (a) Powering mode (b) Reset mode (c) Restoring mode

There are three operating modes in the proposed DC/AC converter; the powering, reset, and restoring modes.

Powering mode: Two diagonal switches $\left(Q_{1}\right.$ and $Q_{4}$, or $Q_{2}$ and $Q_{3}$ ) are closed in the powering mode as shown in Fig. 2(a). The current $i_{L s}$ of the primary inductor is sinusoidally modulated by the full-bridge inverter and transferred to the output through the HF transformer and bi-directional switch. One of two bi-directional switches is closed according to the polarities of the link current and desired output voltage. To minimize the switching losses, the bi-directional switches are turned on/off at the zero link current.

Reset mode: Two upper or lower switches $\left(Q_{1}\right.$ and $Q_{2}$, or $Q_{3}$ and $Q_{4}$ ), or all four switches are opened in the reset mode as shown in Fig. 2(b). The inductor current $i_{L s}$ flows through the diode $D_{f}$ and charges the capacitor $C_{f}$. The primary inductor is generally reset through a flyback winding in the conventional current-fed approaches [9], [10], which has the complexity of the inductor and produces a high impact current. These disadvantages are easily overcome in the proposed scheme. The capacitor voltage $v_{C f}$ can be controlled by the switches $Q_{5}$ and $Q_{6}$ during the active filter operation and is maintained to be higher than the input voltage $V_{d c}$ and the transformer primary voltage $v_{T 1}$.

Restoring mode: Both switches of one inverter leg $\left(Q_{1}\right.$ and $Q_{3}$, or $Q_{2}$ and $Q_{4}$ ), or all four switches are closed as shown in Fig. 2(c). Thus, the inductor current increases with a rate of $V_{d c} / L_{s}$ in the restoring mode while decreases with a rate of $\left(V_{d c^{-}}\right.$ $\left.v_{C f}\right) / L_{s}$ in the reset mode. Therefore, the primary inductor current can be controlled by the appropriate selection of the reset and restoring mode during the interval that the primary current is not transferred to the secondary side.

\section{III.Active Cancellation of $\mathbf{1 2 0 H z}$ Input Harmonic Current}

The input and output powers of the inverter should be balanced in both average and instantaneous senses. The output voltage and current of the DC/AC converter with a sinusoidal output can be expressed as

$$
\begin{aligned}
& v_{o}(t)=\sqrt{2} V_{r m s} \sin \omega t \\
& i_{o}(t)=\sqrt{2} I_{r m s} \sin (\omega t-\phi)
\end{aligned}
$$

where $\phi$ denotes a power factor angle. The instantaneous power is derived from (1) and (2) as

$$
\begin{aligned}
p_{o}(t) & =v_{o}(t) i_{o}(t) \\
& =V_{r m s} I_{r m s} \cos \phi-V_{r m s} I_{r m s} \cos (2 \omega t-\phi)
\end{aligned} .
$$

The average power is defined as

$$
P_{a v}=V_{r m s} I_{r m s} \cos \phi \text {. }
$$

The input current for a constant input voltage of $V_{d c}$ can be represented as 


$$
i_{s}(t)=\frac{V_{r m s} I_{r m s}}{V_{d c}} \cos \phi-\frac{V_{r m s} I_{r m s}}{V_{d c}} \cos (2 \omega t-\phi) .
$$

The second term of the right hand side in (2) is the second order ripple current defined as

$$
i_{r}(t)=-\frac{V_{r m s} I_{r m s}}{V_{d c}} \cos (2 \omega t-\phi) .
$$
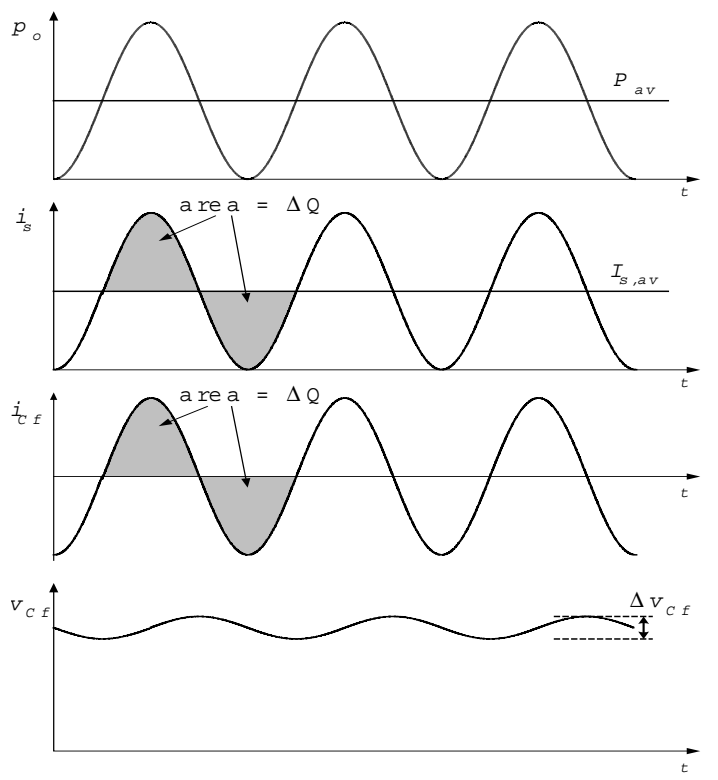

Fig. 3 Output power, input current, capacitor current and voltage waveforms

The basic concept of the proposed technique is that the capacitor $C_{f}$ stores the charge $\Delta Q$ from the DC source during the negative half cycle of the ripple current and then supplies the stored charge to the output during the positive half. Fig. 3 shows the output power, input current, net capacitor current, and capacitor voltage. The charge $\Delta Q$ is equal to the area of the half cycle and can be represented as

$$
\Delta Q=\sqrt{2} I_{r m s} / 60 \pi .
$$

The voltage ripple of the filter capacitor $C_{f}$ can be calculated from (7) as

$$
\Delta v_{C f}=\Delta Q / C_{f} .
$$

Fig. 4 shows the operation of the active harmonic filter, where it is assumed that the filter capacitor voltage $v_{c f}$ is controlled to be higher than $V_{d c}$ and $v_{T I}$. Two operating modes can be considered for the active filter operation. One is the buck mode as shown in Fig. 4(a). The switch $Q_{5}$ and diode $D_{6}$ operates in this mode and the stored charge supplies to the output through the filter inductor $L_{f}$. The other is the boost mode as shown in Fig. 4(a). The current of the filter inductor flows from the source to the filter capacitor and the filter capacitor is charged by the boosting action of the switch $Q_{6}$ and diode $D_{5}$.

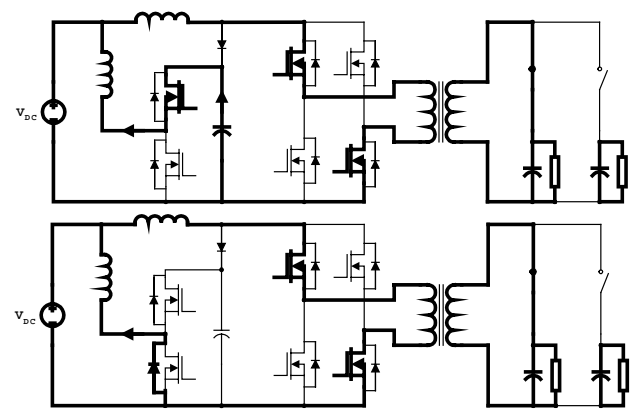

(a)

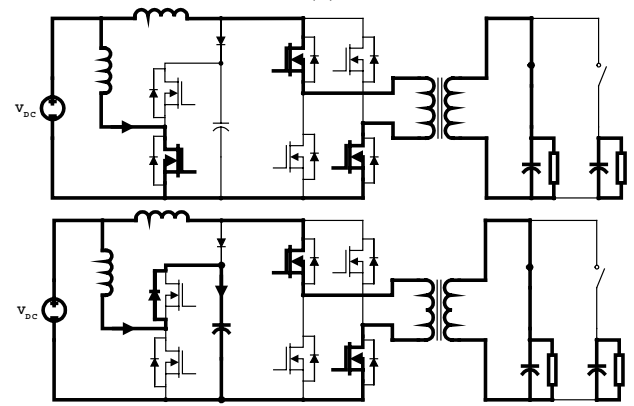

(b)

Fig. 4 Operating modes of active harmonic filter. (a) Buck mode (b) Boost mode

\section{Control Strategy}

\section{A. Control of Output Voltage}

Fig. 5(a) shows the voltage control scheme for the main DC/AC converter. The output voltage is controlled by the PWM of the full-bridge inverter, where $G_{v}(\mathrm{~s})$ is the gain of the voltage control loop. A simple proportional (P) control is used for $G_{v}(\mathrm{~s})$. The bi-directional switches $S_{1}$ ans $S_{2}$ in the secondary side are selected according to the polarities of the control input and link current as shown in Fig. 5(b).

Fig. 6 shows the current control scheme for the primary inductor. The inductor current is controlled by choosing the reset or restoring mode. The current reference can be calculated from the average output power. An integrator with a reset is used as a controller. The reset mode is selected $x_{k}>0$ 
and the restoring mode is selected when $x_{k}<0$, where $x_{k}=\prod_{(k=) T}\left[i_{L s}^{*}(t)-i_{L s}(t)\right] d t$ and $T$ is the switching period.

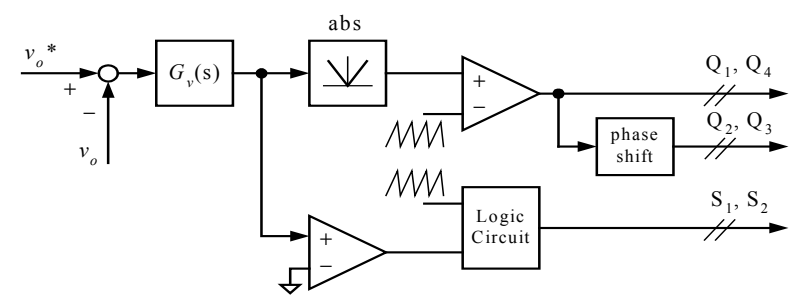

(a)
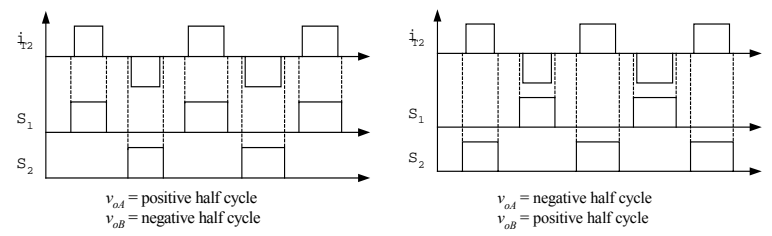

(b)

Fig. 5 Voltage control for current-fed HF link DC/AC converter. (a) Voltage control scheme (b) Switching method of bi-directional switches

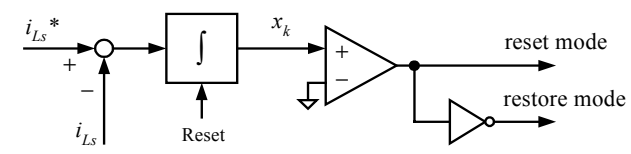

Fig. 6 Current control scheme for the primary inductor

\section{B. Control of Active Harmonic Filter}

Fig. 7 shows the control block diagram for the active harmonic filter. The current reference $i_{L f}{ }^{*}$ can be calculated from the average output power $P_{a v}$ as shown in this figure. The proportional-integral (PI) control is used for the block $G_{f}(\mathrm{~s})$. The control input is applied to the switches by using the PWM. As mentioned, there are two operating modes in the active filter. The buck mode is selected for the positive control input while the boost mode for the negative control input. The switch $Q_{5}$ is controlled in the buck mode and $Q_{6}$ is controlled in the boost mode.

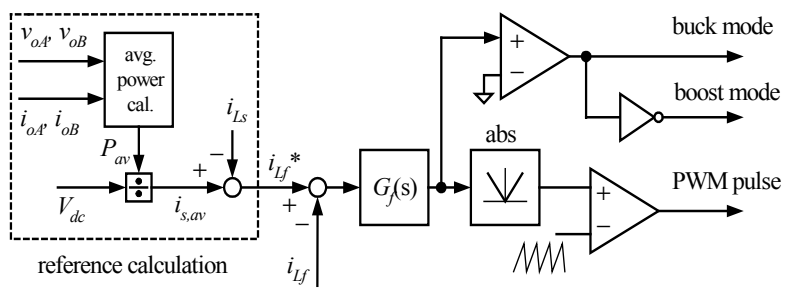

Fig. 7 Control block diagram of active harmonic filter

\section{Simulations}

To verify the usefulness of the proposed converter, the computer simulation is carried out for the actual parameters as follows: $V_{d c}=48 \mathrm{~V}, f_{s}=20 \mathrm{kHz}, L_{s}=500 \mathrm{uH}, L_{f}=500 \mathrm{uH}, C_{o A}=$ $C_{o B}=50 \mathrm{uF}, C_{f}=5600 \mathrm{uF}, n=4$, where $f_{s}$ and $n$ denote the switching frequency and transformer turn ratio, respectively. The gains of the voltage controller is given as $G_{s}(\mathrm{~s})=K_{s}=10$. The PI control is used as for $G_{f}(\mathrm{~s})$ and the gains are given as $K_{p}=100$ and $K_{i}=5000$.

Fig. 8 shows the simulation results of the proposed DC/AC converter for the resistive load of $20 \Omega$ in both phases. Figs. 8 (a) shows two split phase output voltages and line-toline voltage, where the voltage reference is $120 \mathrm{~V}_{\text {rms }}$ with a frequency of $60 \mathrm{~Hz}$. It is shown in this figure that the proposed converter produces the desired output voltages with excellent waveforms. Figs. 8 (b), (c), (d), and (e) represents the operation of the active harmonic filter, and shows the primary inductor current, filter inductor current, input current, and filter capacitor voltage, respectively. It is noted in these figures that the harmonic current of $120 \mathrm{~Hz}$ is effectively eliminated by employing the proposed active harmonic filter. Fig. 9 shows the simulation results for the $R-L$ load, where $R_{L A}=R_{L B}=20 \Omega$ and the load power factor is 0.8. Figs. 9(a), (b), and (c) show the output voltage $v_{o A}$, current $i_{L A}$, and input current. Fig. 10 shows the simulation results for the rectifier load. Figs. 10(a), (b), and (c) show the output voltage $v_{o A}$, load current, and input current. It can be shown in Figs. 9 and 10 that the proposed DC/AC converter also provides a good voltage waveform and the capability of eliminating the $120 \mathrm{~Hz}$ input harmonic current for the $R-L$ and rectifier loads.

\section{Conclusions}

This paper has presented a new current-fed HF link $\mathrm{DC} / \mathrm{AC}$ converter with the capability of the $120 \mathrm{~Hz}$ harmonic rejection for fuel cell applications. The proposed converter is a single stage approach and has a simple transformer structure. The active harmonic filter consists of the two switches and one electrolytic capacitor, and effectively eliminates the input 
harmonic current. The operation of the DC/AC converter and harmonic filter has been investigated. The computer simulation was carried out for the actual circuit parameters and the results well verify the validity of the proposed converter with the active filter. It is expected from the results that the proposed scheme is used for the residential fuel cell power generation systems as an effective low cost solution. The experimental verification is being carried out for the prototype converter system using the TMS320F2407 DSP controller. The results will be presented in the final paper.

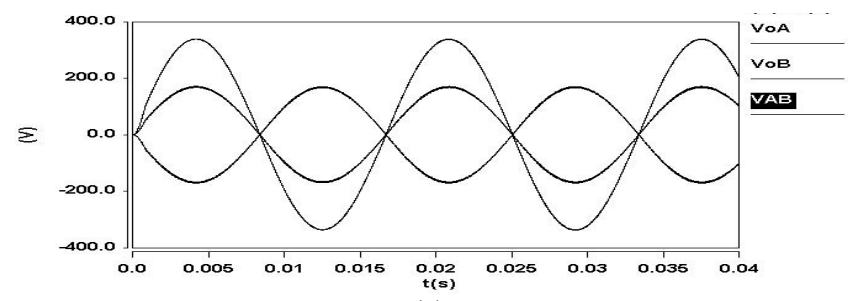

(a)

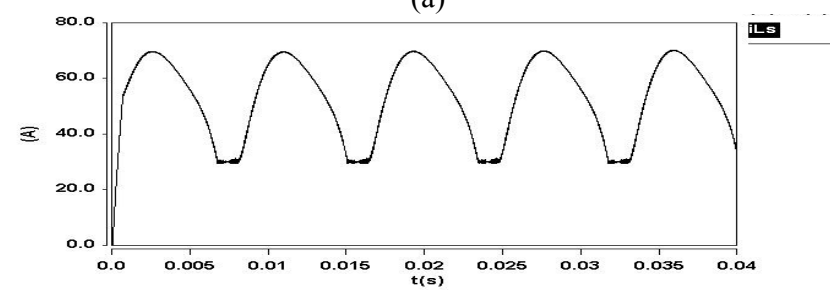

(b)

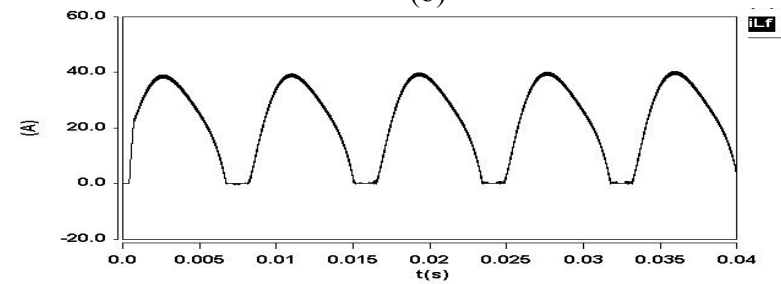

(c)

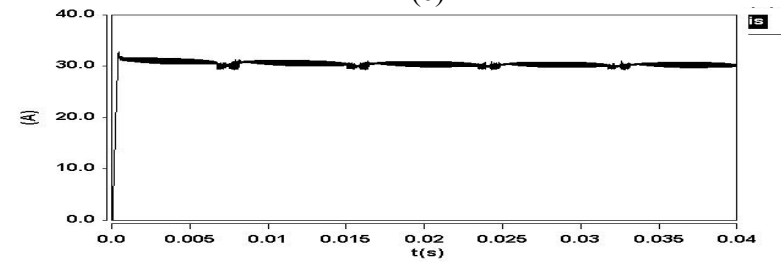

(d)

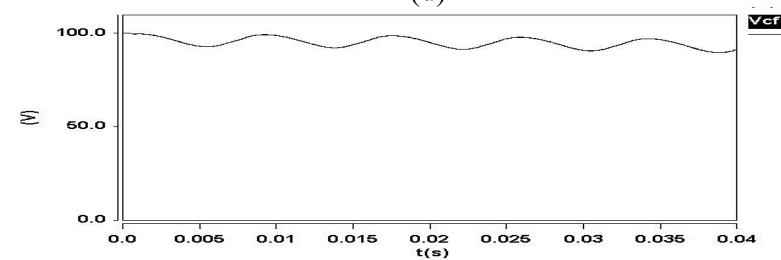

(e)

Fig. 8 Simulation results of proposed DC/AC converter for resistive load $\left(R_{L A}=R_{L B}=20 \Omega\right.$ ). (a) $v_{O A}, v_{O B}$, and $v_{A B}$ (b) $i_{L s}$ (c) $i_{L f} \quad$ (d) $i_{s} \quad$ (e) $v_{c f}$

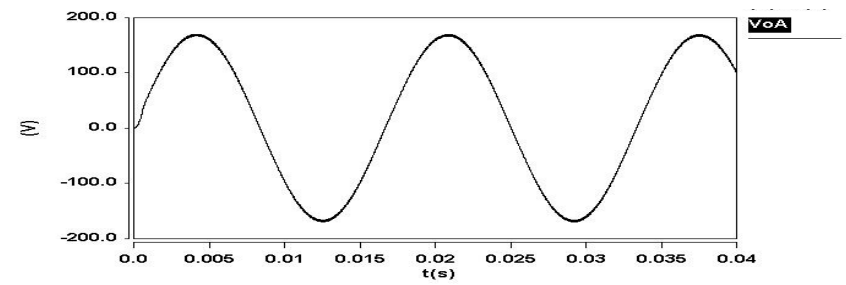

(a)

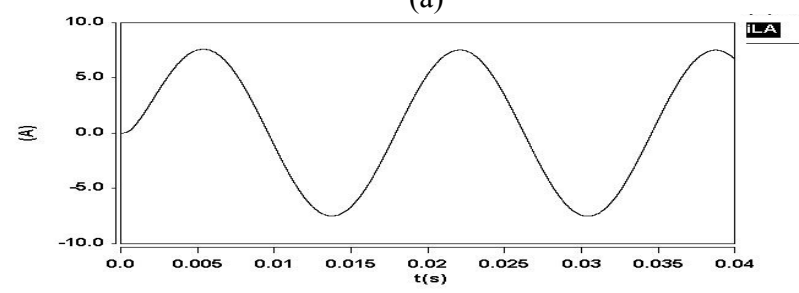

(b)

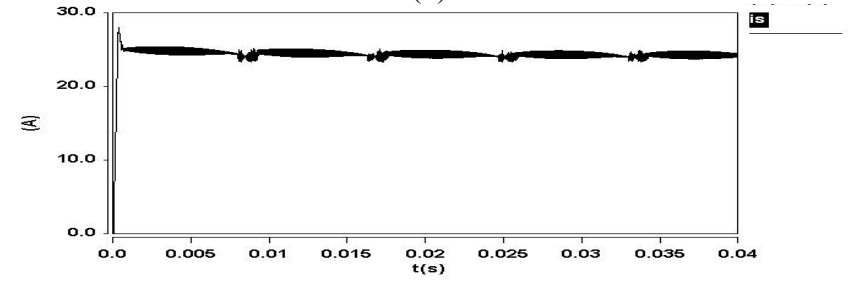

(c)

Fig. 9 Simulation results of proposed DC/AC converter for $R-L$

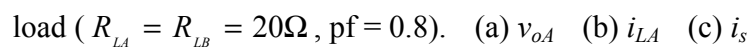
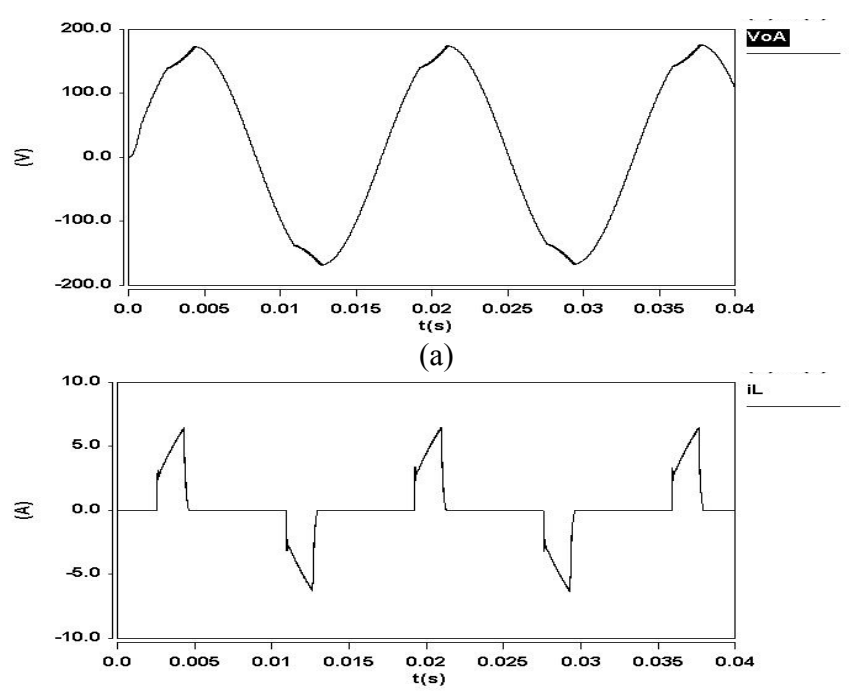

(b)

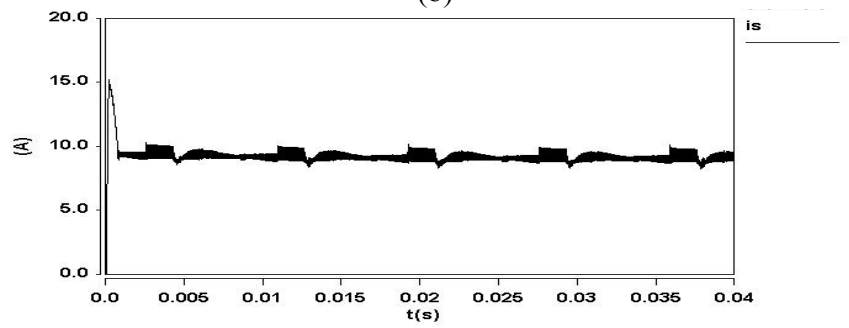

(c)

Fig. 10 Simulation results of proposed DC/AC converter for rectifier load ( Rectifier $C=200 \mu F, R_{L}=200 \Omega$ ). (a) $v_{o A} \quad$ (b) $i_{L} \quad$ (c) $i_{S}$ 